\title{
First space-based derivation of the global atmospheric methanol emission fluxes
}

\author{
T. Stavrakou ${ }^{1}$, A. Guenther ${ }^{2}$, A. Razavi ${ }^{3}$, L. Clarisse ${ }^{3}$, C. Clerbaux ${ }^{4,3}$, P.-F. Coheur ${ }^{3}$, D. Hurtmans ${ }^{3}$, F. Karagulian ${ }^{3, *}$, \\ M. De Mazière ${ }^{1}$, C. Vigouroux ${ }^{1}$, C. Amelynck ${ }^{1}$, N. Schoon $^{1}$, Q. Laffineur ${ }^{5}$, B. Heinesch ${ }^{5}$, M. Aubinet ${ }^{5}$, C. Rinsland ${ }^{6}$, \\ and J.-F. Müller ${ }^{1}$ \\ ${ }^{1}$ Belgian Institute for Space Aeronomy, Avenue Circulaire 3, 1180, Brussels, Belgium \\ ${ }^{2}$ Atmospheric Chemistry Division, National Center for Atmospheric Research, 1850 Table Mesa Drive, Boulder Colorado, \\ 80305, USA \\ ${ }^{3}$ Spectroscopie de l'Atmosphère, Service de Chimie Quantique et Photophysique, Université Libre de Bruxelles, Belgium \\ ${ }^{4}$ UPMC Univ. Paris 06, Université Versailles St-Quentin, CNRS/INSU, LATMOS-IPSL, Paris, France \\ ${ }^{5}$ Gembloux Agro-Bio Tech, University of Liège, Unité de Physique des Biosystèmes, Avenue de la Faculté d'Agronomie 8 , \\ 5030 Gembloux, Belgium \\ ${ }^{6}$ NASA Langley Research Center, Hampton, Virginia, USA \\ "now at: European Commission, Joint Research Centre (JRC), 21027, Ispra, Italy
}

Received: 3 December 2010 - Published in Atmos. Chem. Phys. Discuss.: 11 February 2011

Revised: 4 May 2011 - Accepted: 19 May 2011 - Published: 25 May 2011

\begin{abstract}
This study provides improved methanol emission estimates on the global scale, in particular for the largest methanol source, the terrestrial biosphere, and for biomass burning. To this purpose, one complete year of spaceborne measurements of tropospheric methanol columns retrieved for the first time by the thermal infrared sensor IASI aboard the MetOp satellite are compared with distributions calculated by the IMAGESv2 global chemistry-transport model. Two model simulations are performed using a priori biogenic methanol emissions either from the new MEGANv2.1 emission model, which is fully described in this work and is based on net ecosystem flux measurements, or from a previous parameterization based on net primary production by Jacob et al. (2005). A significantly better model performance in terms of both amplitude and seasonality is achieved through the use of MEGANv2.1 in most world regions, with respect to IASI data, and to surface- and air-based methanol measurements, even though important discrepancies over several regions are still present. As a second step of this study, we combine the MEGANv2.1 and the IASI column abundances over continents in an inverse modelling scheme based on the adjoint of the IMAGESv2 model to generate an improved global methanol emission source. The global optimized source totals $187 \mathrm{Tg} \mathrm{yr}^{-1}$ with a contribution of $100 \mathrm{Tg} \mathrm{yr}^{-1}$ from plants, only slightly lower than the a priori
\end{abstract}

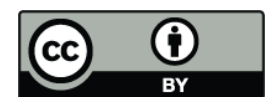

Correspondence to: T. Stavrakou (jenny@aeronomie.be)
MEGANv2.1 value of $105 \mathrm{Tg} \mathrm{yr}^{-1}$. Large decreases with respect to the MEGANv2.1 biogenic source are inferred over Amazonia (up to $55 \%$ ) and Indonesia (up to $58 \%$ ), whereas more moderate reductions are recorded in the Eastern US (20-25\%) and Central Africa (25-35\%). On the other hand, the biogenic source is found to strongly increase in the arid and semi-arid regions of Central Asia (up to a factor of 5) and Western US (factor of 2), probably due to a source of methanol specific to these ecosystems which is unaccounted for in the MEGANv2.1 inventory. The most significant error reductions achieved by the optimization concern the derived biogenic emissions over the Amazon and over the Former Soviet Union. The robustness of the derived fluxes to changes in convective updraft fluxes, in methanol removal processes, and in the choice of the biogenic a priori inventory is assessed through sensitivity inversions. Detailed comparisons of the model with a number of aircraft and surface observations of methanol, as well as new methanol measurements in Europe and in the Reunion Island show that the satellite-derived methanol emissions improve significantly the agreement with the independent data, giving thus credence to the IASI dataset.

\section{Introduction}

Methanol $\left(\mathrm{CH}_{3} \mathrm{OH}\right)$ has been identified as one of the major organic compounds in the troposphere, most abundant above forests during the growing season with measured

Published by Copernicus Publications on behalf of the European Geosciences Union. 
concentrations of the order of several ppb (e.g. Williams et al., 2001; Schade and Goldstein, 2006; Karl et al., 2007). Due to its influence on the background tropospheric photochemistry, its influence on $\mathrm{OH}$ concentrations in the boundary layer, its contribution to the tropospheric ozone production, and the production of formaldehyde upon its oxidation by $\mathrm{OH}$, methanol became the subject of many literature studies with focus on (i) process-based emission mechanisms (e.g. Macdonald and Fall, 1993; Fall and Benson, 1996; Hüve et al., 2007; Folkers et al., 2008); (ii) modelling studies attempting to derive global methanol budget closures (e.g. Galbally and Kirstine, 2002; Jacob et al., 2005; Millet et al., 2008); (iii) field and aircraft measurements (e.g. Singh et al., 2000; Karl et al., 2003a; Millet et al., 2004; Spirig et al., 2005; Mao et al., 2006).

The above studies have been recently complemented by newly acquired space-based methanol observations in the upper troposphere from the ACE-FTS/SCISAT-1 solar occultation instrument (Dufour et al., 2006), and from the TES/AURA (Beer et al., 2008) and IASI/MetOp-A (Razavi et al., 2011) infrared nadir-looking probers of the lower troposphere.

Although it is agreed that plant emissions represent the major part of the methanol flux from the terrestrial ecosystems, much uncertainty remains concerning their magnitude and global distribution. A number of modelling studies attempting to quantify the plant growth and decay source provided a wide range of values for the global annual emission estimates, from $95 \mathrm{Tg}$ (Singh et al., 2000) up to $280 \mathrm{Tg}$ (Heikes et al., 2002). Aside from the plant source, oceans are hypothesized to constitute an important source of methanol which is required in order to explain observed methanol concentrations in the marine boundary layer (Heikes et al., 2002). This source is, however, outweighted by a more significant ocean sink (Millet et al. (2008), Heikes et al. (2002), this study). In addition to natural emissions from plants and oceans, methanol is also released from anthropogenic activities and biomass burning at much lower rates, contributing less than $10 \%$ of the estimated global source. The main methanol removal pathways are oxidation by $\mathrm{OH}$ and dry deposition, whereas wet deposition constitutes a minor sink.

In this work we present first a new algorithm (MEGANv2.1) for deriving methanol emissions from plants. As opposed to previous emission models based on the net primary production from the earth ecosystems (Galbally and Kirstine, 2002; Jacob et al., 2005), the MEGANv2.1 model is based on net ecosystem fluxes, and accounts for the effects of light, temperature, and leaf age, in a similar way as for isoprene emissions in the MEGAN model (Guenther et al., 2006). The derived MEGANv2.1 inventory, as well as a previous biogenic methanol emission inventory by Jacob et al. (2005) are implemented in the global IMAGESv2 chemistry-transport model used to simulate methanol concentrations. An inverse modelling experiment is designed using the MEGANv2.1 biogenic source as a priori and constrained by methanol columns from the newly released global IASI dataset (Razavi et al., 2011) in order to derive updated global methanol emissions. The inversion study is based on the adjoint module of IMAGESv2 (Müller and Stavrakou, 2005), and on the grid-based approach for retrieving emissions of reactive species (Stavrakou and Müller, 2006; Stavrakou et al., 2008, 2009b,c). The initial and updated emissions are compared on the global and regional scale, with focus on seasonal variations of methanol columns, especially over regions (Tropics, Europe, Asia, Africa) where observations from other platforms are either scarce or not available. Furthermore, the model results before and after optimization are evaluated against previous modelling work, available aircraft methanol data, and a compiled set of literature in situ measurements from different continents. Comparisons are also presented with FTIR column data from the Kitt Peak Observatory in the western US, and newly retrieved measurements from a European forested site and FTIR column data from the subtropical site of the Reunion Island in the Indian Ocean.

The article is organized as follows. In Sect. 2 a literature overview on methanol releases by plants is presented, followed by a thorough description of the MEGANv2.1 emission model for methanol emissions, and its implementation in a canopy model to derive global methanol emission estimates. The methanol ocean source and sink are described in Sect. 3. The IMAGESv2 global model used to simulate methanol concentrations and the annual a priori methanol budget are the subject of Sect. 4. Section 5 is dedicated to the presentation of the IASI satellite data used to constrain the inversion, and to a description of the inversion setup. Multi-instrument independent observational methanol data, presented in Sect. 6, are used to evaluate how the model performs before and after optimization and also to validate the satellite dataset. The a priori and inversion results are discussed in Sects. 7 and 8. The errors on the a posteriori IASIderived fluxes are computed in Sect. 9, and the dependence of the retrieved fluxes on model uncertainties is addressed in Sect. 10. Our main conclusions are drawn in Sect. 11.

\section{Methanol released by plants}

\subsection{Background}

Methanol production is ubiquitous among higher plants, as a result of the demethylation of pectins, complex polysaccharides acting as tissue firming agents in the cell walls of plants. The demethylation is catalyzed by pectin methylesterases, cell wall enzymes involved in plant growth and development (Fall and Benson, 1996), but also in plant defensive response against herbivore attacks (Körner et al., 2009), and produces methanol as a major end-product exiting leaves through stomata during transpiration (Schink and Zeikus, 
1980; Nemecek-Marshall et al., 1995; Fall and Benson, 1996). The methanol leaf emission is controlled by leaf temperature and light (Folkers et al., 2008), and by the stomatal conductance and evapotranspiration (Macdonald and Fall, 1993; Niinemets and Reichstein, 2003a,b; Hüve et al., 2007). The emissions exhibit a pronounced diel profile peaking in the morning upon stomatal opening when methanol accumulated at night in the intracellular space is released in the atmosphere (Hüve et al., 2007).

Growing leaves were found to emit about four times more methanol than adult leaves in the case of the Mexican cotton plant (Hüve et al., 2007). Although large methanol emission rates are often associated with young, growing leaves, a substantial portion of the annual emission of methanol from a broadleaf forest is associated with mature and senescing canopies (Karl et al., 2003a). However, the emission generally declined with increasing leaf age after leaf expansion (Nemecek-Marshall et al., 1995). In addition, high amounts of methanol have been reported over agricultural grassland during and after cutting, as well as during the hay drying phase (Davison et al., 2008). Aside from plant growth and development, which are by far the dominant methanolgenerating mechanisms, different processes, like e.g. root and fruit growth (Fall and Benson, 1996), or the abiological production of oxidized VOCs from the decay of dead plant material (Warneke et al., 1999) also produce methanol at lower rates. However, literature studies about such processes are generally either limited or lacking.

Bottom-up biogenic methanol emission inventories require extrapolation, often in a crude way, of the limited sets of available laboratory measurements of methanol fluxes from leaves. Guenther et al. (1995) estimated the global annual methanol emission at more than $320 \mathrm{Tg}$ based on flux measurements from Macdonald and Fall (1993), a value close to the value $\left(280 \mathrm{Tg} \mathrm{yr}^{-1}\right)$ reported by Heikes et al. (2002). Galbally and Kirstine (2002) assumed that the mass of methanol emitted by a plant over a given time period is linearly related to the net primary carbon production, and estimated the ratio of methanol carbon emission to net primary carbon production at $0.024 \%$ for grasses and to $0.11 \%$ for other higher plants. Their resulting best estimate for the global methanol emission amounts to $100 \mathrm{Tg} \mathrm{yr}^{-1}$, three times lower compared to the Tie et al. (2003) estimate. Based on the Galbally and Kirstine (2002) plant model and on the net primary production and heterotrophic transpiration calculated with a biogeochemical model, the plant growth and decay sources of methanol have been estimated at 128 and $23 \mathrm{Tg} \mathrm{yr}^{-1}$, respectively (Jacob et al., 2005), whereas a more recent study constrained by aircraft measurements suggested a strong reduction of the plant growth source (by $38 \%$, Millet et al., 2008) and indicated possible shortcomings in the NPP-based parameterization scheme.

The Model of Emissions of Gases and Aerosols from Nature (MEGAN, Guenther et al., 2006), is extended to include methanol emissions (MEGANv2.1), as described be- low. The employed modelling approach, different from the one based on the NPP, makes use of the net ecosystem flux that integrates both emission and deposition processes from all ecosystem components including foliage, trunks, leaf litter and soil microbes. The methanol flux algorithm, the observations it is based on, and the implementation of the algorithm in a canopy environment model to generate global methanol emissions from vegetation are the subject of the two following sections.

\subsection{The MEGANv2.1 algorithm}

The net methanol flux, $F$ (in $\mu \mathrm{g} \mathrm{m}^{-2} \mathrm{~h}^{-1}$ ) from a terrestrial landscape into the above canopy atmosphere is estimated as

$F=E-L$,

where $E$ is the methanol emission rate and $L$ the methanol loss rate. The area average flux within a model grid cell is calculated as the area weighted average of the fluxes in each landcover type (e.g. broadleaf trees, needleleaf trees, shrubs, crops, grass). The methanol loss rate can be calculated from the above canopy methanol concentration and a parameterized dry deposition velocity. A typical value for dry deposition flux is $50 \mu \mathrm{g} \mathrm{m}^{-2} \mathrm{~h}^{-1}$.

The methanol emission rate is estimated as

$E=\gamma_{\text {age }} \cdot \gamma_{\mathrm{CE}} \cdot \epsilon$,

where $\epsilon$ is the emission factor associated with the standard conditions defined in Guenther et al. (2006) $\left(800 \mu \mathrm{g} \mathrm{m}^{-2} \mathrm{~h}^{-1}\right.$ for northern temperate and boreal broadleaf trees, needleleaf trees, shrubs and crops, and $400 \mu \mathrm{g} \mathrm{m}^{-2} \mathrm{~h}^{-1}$ for grasses and other broadleaf trees). These emission factors are based on whole ecosystem net methanol flux measurements reported by 17 studies that characterized various ecosystems including tropical forest (Geron et al., 2002; Karl et al., 2004, 2007; Langford et al., 2010), warm conifer forest (Karl et al., 2005), cool temperate conifer forest (Schade and Goldstein, 2001; Baker et al., 2001; Karl et al., 2002), temperate broadleaf forest and plantation (Spirig et al., 2005; Karl et al., 2003a; Jardine et al., 2008), boreal forest (Rinne et al., 2007), croplands (Warneke et al., 2002; Schade and Custer, 2004) and grassland (Kirstine et al., 1998; Fukui and Doskey, 1998; Ruuskanen et al., 2010). Among these studies, Kirstine et al. (1998) and Fukui and Doskey (1998) have used whole ecosystem enclosure techniques with gas chromatography analysis to quantify emissions from grasslands, Schade and Goldstein (2001), Baker et al. (2001) and Geron et al. (2002) used above canopy relaxed eddy accumulation with gas chromatography analysis to measure methanol fluxes above forests, whereas all the other studies used protontransfer reaction mass spectroscopy (PTR-MS) and the eddy covariance, or disjunct eddy covariance, approach (see Karl et al., 2002). The daytime fluxes reported by these studies for warm, sunny conditions range from no emissions (or a small net uptake) to a net emission of about $3500 \mu \mathrm{g} \mathrm{m}^{-2} \mathrm{~h}^{-1}$. 
Methanol emission factors based on the relaxed eddy accumulation approach are a factor of 3 (for broadleaf trees) to 5 (for needleleaf trees) higher than emission factors based on the eddy covariance technique. The average values for northern temperate and boreal broadleaf trees and needleleaf trees are not significantly different and the MEGANv2.1 methanol emission factor for northern forests and all shrublands is based on the median value of these studies. The lower emission rates for tropical broadleaf forests are based on recent measurements indicating lower emissions for these landscapes (Karl et al., 2007; Langford et al., 2010). The few measurements reported for croplands include methanol emission fluxes of alfalfa (Warneke et al., 2002) that are much higher than the forest values, and emission fluxes from ryegrass (Schade and Custer, 2004), that are much lower. Since the MEGAN landcover data do not distinguish between high and low emission crops, the value used for forests is currently used for all crops. The lower emission factor assigned to grasslands is in agreement with the model approach of Galbally and Kirstine (2002). Earlier enclosure studies of grass pastures in US (Fukui and Doskey, 1998) and Australia (Kirstine et al., 1998) reported very low methanol emissions while more than a factor of 3 higher emissions were observed recently from a grassland meadow in Austria using a PTRMS eddy covariance flux measurement technique (Ruuskanen et al., 2010). The differences could be due to the presence of forbs or different grass species and future methanol modelling efforts may need to distinguish between different grassland types.

Emission variations associated with canopy environment and leaf age are accounted for through the dimensionless emission activity factors $\gamma_{\mathrm{CE}}$ and $\gamma_{\text {age }}$. The canopy-weighted leaf age emission activity factor for methanol is calculated as

$\gamma_{\text {age }}=F_{\text {new }} A_{\text {new }}+F_{\text {gro }} A_{\text {gro }}+F_{\text {mat }} A_{\text {mat }}+F_{\text {sen }} A_{\text {sen }}$,

where the canopy fractions $F$ of the new, growing, mature, and senescing groups are calculated according to Guenther et al. (2006) and the relative methanol emission rates assigned to each canopy fraction for $A_{\text {new }}, A_{\text {gro }}, A_{\text {mat }}$, and $A_{\text {sen }}$ are equal to $3.5,3,1$, and 1.2 , respectively. The parameters used in the leaf age algorithm are based on the results of Harley et al. (2007) and Karl et al. (2003a). The leaf age activity factor can be applied to both evergreen and deciduous canopies, but will typically be close to 1 for evergreen canopies. The canopy environment activity factor is a function of temperature, photosynthetic photon flux density (PPFD), and leaf area index (LAI), and can be calculated either using a multi-layer canopy environment model that calculates light and temperature for sunlit and shaded leaves or by using parameterized equations for each component (temperature, phorosynthetically active radiation, LAI) that are based on simulations with the multi-layer sun/shade canopy model (Guenther et al., 2006). Using a multi-layer model, the canopy average value is estimated as

$\gamma_{\mathrm{CE}}=C_{\mathrm{CE}} \cdot \gamma_{\mathrm{PT}} \cdot \mathrm{LAI}$,

where $C_{\mathrm{CE}}$ is equal to 0.58 , and $\gamma_{\mathrm{PT}}$ is the weighted average, for all leaves, of activity factors that account for the influence of light and temperature, and LAI is the leaf area index.

Methanol emissions increase exponentially with increasing temperature and tend to have elevated values with higher PPFD (Harley et al., 2007). MEGANv2.1 assumes that all biogenic VOCs can be produced by both light dependent and light independent emission processes. The leaf level temperature and light response is calculated as

$\gamma_{\mathrm{PT}}=(1-\mathrm{LDF}) \cdot \gamma_{\mathrm{T}-\mathrm{li}}+\mathrm{LDF} \cdot \gamma_{\mathrm{P}} \cdot \gamma_{\mathrm{T}-\mathrm{ld}}$,

where the LDF is the light-dependent fraction of the emissions at standard conditions $(=0.8$ for methanol $), \gamma_{\mathrm{P}}$ is the light response of methanol emissions, $\gamma_{\mathrm{T}-\mathrm{ld}}$ is the temperature response for the light-dependent fraction of the emissions, $\gamma_{\mathrm{T}-\mathrm{li}}$ is the temperature response for the remainder of the emissions that are not light dependent.

The activity factors $\gamma_{\mathrm{P}}$ and $\gamma_{\mathrm{T}-\mathrm{ld}}$ for methanol are calculated using the isoprene light and temperature dependent equations described by Guenther et al. (2006), expressed as

$\gamma_{\mathrm{T}-\mathrm{ld}}=E_{\mathrm{opt}} \cdot\left[C_{\mathrm{T} 2} \cdot e^{C_{\mathrm{T} 1} \cdot x} /\left(C_{\mathrm{T} 2}-C_{\mathrm{T} 1} \cdot\left(1-e^{C_{\mathrm{T} 2} \cdot x}\right)\right)\right]$,

where for methanol the values of the coefficients are $C_{\mathrm{T} 1}=$ $60, C_{\mathrm{T} 2}=230, x=\left[\left(1 / T_{\mathrm{opt}}\right)-(1 / T)\right] / 0.00831$, and $T$ is the leaf temperature (K). At the MEGAN standard conditions, $E_{\mathrm{opt}}=1.61$ and $T_{\mathrm{opt}}=313 \mathrm{~K}$. These may vary with past light and temperature conditions, as is the case for isoprene (Guenther et al., 2006), but are held constant in MEGANv2.1 due to a lack of observations for characterizing these processes. For light independent emissions we have

$\gamma_{\mathrm{T}-\mathrm{li}}=\exp (\beta(T-303))$,

where $T$ is the leaf temperature and $\beta$ is the temperature response factor which is assigned a value of $0.08 \mathrm{~K}^{-1}$ for methanol. The observed values for $\beta$ from above canopy field studies ranges from 0.01 to 0.16 with a median value of 0.073 . A similar average value of $0.08 \mathrm{~K}^{-1}$ is reported by Harley et al. (2007), based on controlled enclosure measurements on crops, needleleaf and broadleaf trees.

\subsection{Global biogenic methanol emission inventory}

To determine the height-dependent leaf temperature and radiation fluxes inside the canopy, we use the Model for HYdrocarbon emissions by the CANopy (MOHYCAN) (Müller et al., 2008). The model calculates PPFD and leaf temperature at eight canopy levels based on canopy-top estimates for the visible and near-infrared radiative fluxes (including their diffuse and direct components), air temperature, wind speed, and relative humidity. These estimates are obtained 

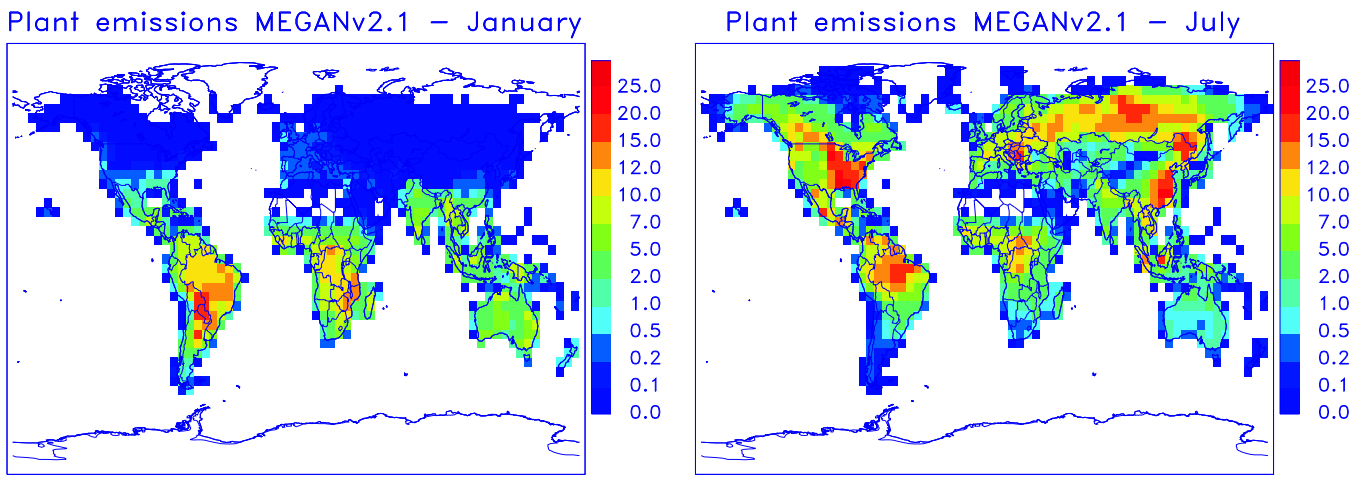

Fig. 1. Global biogenic methanol emissions in January and in July calculated using the MEGANv2.1 algorithm and the MOHYCAN canopy model, and downgraded to the IMAGESv2 model resolution $\left(4^{\circ} \times 5^{\circ}\right)$. Units are $10^{10} \mathrm{~mol} \mathrm{~cm}^{-2} \mathrm{~s}^{-1}$.

from ERA-Interim fields for the downward solar radiation, cloud cover fraction, air temperature and wind speed directly above the canopy, provided every $6 \mathrm{~h}$ and re-gridded at a resolution of $0.5^{\circ} \times 0.5^{\circ}$ between 2003 and 2009. The emissions are calculated for both cloudy and clear conditions with cloud optical depth being estimated based on the cloud cover fraction and the solar radiation flux. Leaf area index data are obtained from the collection 5 MODIS 8-day product generated by compositing daily Aqua and Terra observations (Shabanov et al., 2007) at $1 \mathrm{~km}^{2}$ resolution. This dataset is available between July 2002 and the present date via ftp at the MODIS Land site (ftp://e4ft101u.ecs.nasa.gov/MOTA/ MCD15A2.005). The LAI of vegetated areas is determined by dividing the MODIS LAI by the vegetated fraction of the grid cell (Guenther et al., 2006).

Global monthly averaged methanol fluxes are generated at a resolution of $0.5^{\circ}$ for all years between 2003 and 2009 and are available at the MOHYCAN model website (http: //tropo.aeronomie.be/models/mohycan.htm). In the following we present methanol emission fluxes for 2009. The globally estimated source of methanol for this year amounts to $105 \mathrm{Tg}$. Monthly averaged global methanol fluxes in January and July at $4^{\circ} \times 5^{\circ}$ resolution are illustrated in Fig. 1 .

\section{Modelling the oceanic methanol flux}

The parameterization used for the emission and uptake of methanol by the oceans follows the approach of Millet et al. (2008). The flux of methanol is expressed by the Liss and Slater (1974) two-layer model :

$F=K_{\mathrm{w}}\left(C_{\mathrm{g}} H^{-1}-C_{\mathrm{w}}\right)\left(\mathrm{mol} \mathrm{cm}^{-2} \mathrm{~s}^{-1}\right)$,

where $C_{\mathrm{g}}$ and $C_{\mathrm{w}}$ (in $\mathrm{mol} \mathrm{cm}^{-3}$ ) are the methanol concentrations in the atmosphere and in water, respectively,

$H^{-1}=K_{\mathrm{H}} R T$

with $K_{\mathrm{H}}\left(\right.$ mole $\left.^{-1} \mathrm{~atm}^{-1}\right)$ being the Henry's law constant for methanol (Snider and Dawson, 1985), $R$ the ideal gas constant $\left(=8.205 \times 10^{-2} 1 \mathrm{~atm}^{\mathrm{mole}}{ }^{-1} \mathrm{~K}^{-1}\right)$, and $T$ the water temperature (in $\mathrm{K}$ ). The term $K_{\mathrm{w}}$ is expressed by

$K_{\mathrm{w}}^{-1}=k_{\mathrm{w}}^{-1}+\left(k_{\mathrm{g}} H\right)^{-1}$,

where $k_{\mathrm{g}}$ and $k_{\mathrm{w}}$ are the gas phase and liquid phase transfer velocity, respectively, parameterized according to Johnson (2010), based on 6-hourly distributions of surface ocean temperature and wind velocity at $10 \mathrm{~m}$ above the ocean obtained from the ECMWF ERA-Interim re-analysis.

Annually averaged oceanic methanol emission fluxes and deposition velocity $\left(=\left(H / k_{\mathrm{w}}+1 / k_{\mathrm{g}}\right)^{-1}, \mathrm{~cm} \mathrm{~s}^{-1}\right)$, calculated using the above parameterization are shown in Fig. 2. The global methanol oceanic source amounts to $43 \mathrm{Tg}$, in good agreement with Heikes et al. (2002) $\left(30 \mathrm{Tg} \mathrm{yr}^{-1}\right)$, whereas the calculated uptake with the IMAGESv2 model is estimated at $48-56 \mathrm{Tg}$ (Table 1), resulting in a global annual net methanol sink of ca. $5-13 \mathrm{Tg} \mathrm{yr}^{-1}$. This sink is largest $\left(>7 \times 10^{9} \mathrm{~mol} \mathrm{~cm}^{-2} \mathrm{~s}^{-1}\right)$ near continental coasts, and becomes a weak source over open water regions, in agreement with reported results by Millet et al. (2008). However, the ocean source (and sink) estimated by Millet et al. (2008) is twice as large as our estimate. This difference stems mainly from the use of an older parameterization (Asher, 1997) for the gas-phase transfer coefficient $k_{\mathrm{g}}$ in Millet et al. (2008). In fact, the use of Millet et al. (2008) parameterization in our model would result in an ocean source estimate of $90 \mathrm{Tg} \mathrm{yr}^{-1}$, very close to the Millet et al. (2008) reported value $\left(85 \mathrm{Tg} \mathrm{yr}^{-1}\right)$.

\section{Methanol simulated with IMAGESv2}

The IMAGESv2 global chemistry-transport model runs at $4^{\circ} \times 5^{\circ}$ resolution and is resolved at 40 vertical levels from the surface up to the pressure of $44 \mathrm{hPa}$. It calculates the daily averaged concentrations of 100 trace gases using a time step of 1 day, while accounting for the impact of diurnal variations of the chemical compounds through correction factors computed via a diurnal 

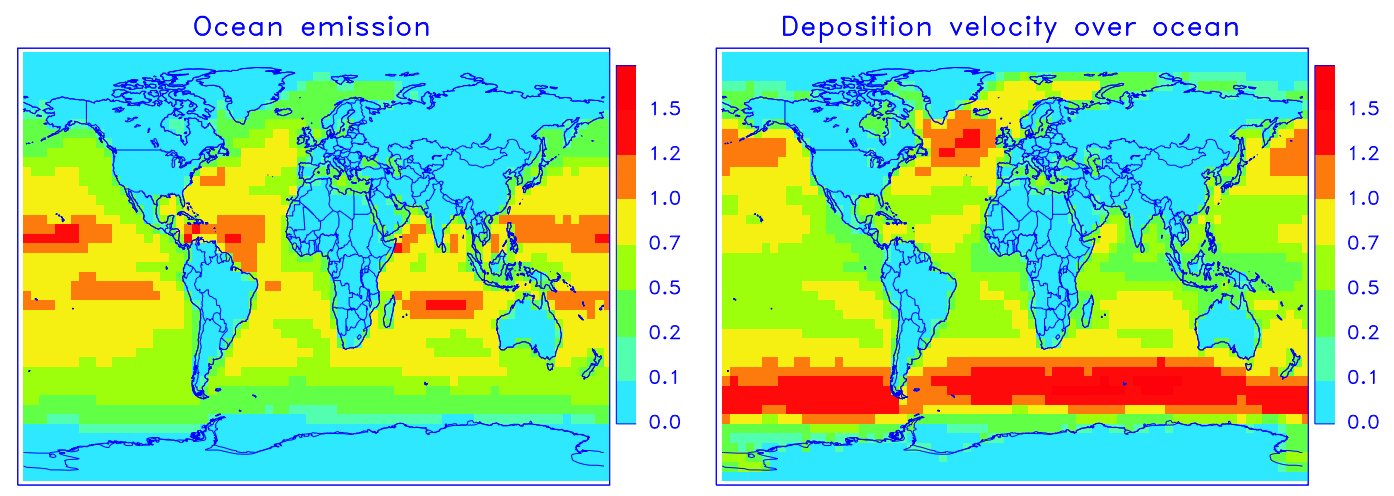

Fig. 2. Annually averaged methanol ocean emission fluxes (left, in $10^{10} \mathrm{~mol} \mathrm{~cm}{ }^{-2} \mathrm{~s}^{-1}$ ), and deposition velocity over ocean (right), expressed in $\mathrm{cm} \mathrm{s}^{-1}$

Table 1. Performed simulations and global a priori and a posteriori annual methanol budgets calculated with IMAGESv2 and comparison with previous work by Millet et al. (2008).

\begin{tabular}{|c|c|c|c|c|}
\hline \multicolumn{5}{|c|}{ Performed Simulations } \\
\hline Forward & S1 & \multirow{3}{*}{\multicolumn{3}{|c|}{$\begin{array}{l}\text { uses biogenic source from Jacob et al. (2005) } \\
\text { uses the MEGANv2.1 biogenic source } \\
\text { based on S2, is constrained by IASI data }\end{array}$}} \\
\hline Forward & S2 & & & \\
\hline Inversion & OptS2 & & & \\
\hline \multicolumn{5}{|c|}{ Sources $\left(\operatorname{Tg~yr}^{-1}\right)$} \\
\hline Simulations & $\mathrm{S} 1$ & $\mathrm{~S} 2$ & OptS2 & Millet et al. (2008) \\
\hline Anthropogenic & 9.3 & 9.3 & 9.3 & $17^{\mathrm{a}}$ \\
\hline Pyrogenic & 5.3 & 5.3 & 4.3 & \\
\hline Biogenic & 151 & 104.7 & 100 & $103^{\mathrm{b}}$ \\
\hline Oceanic & 42.7 & 42.7 & 42.7 & 85 \\
\hline $\begin{array}{l}\text { Atmospheric } \\
\text { production }\end{array}$ & 30.7 & 30.9 & 31.1 & 37 \\
\hline Total & 239 & 193 & 187 & 242 \\
\hline \multicolumn{5}{|c|}{ Sinks $\left(\mathrm{Tg} \mathrm{yr}^{-1}\right)$} \\
\hline OH oxidation & 131 & 107 & 108 & 88 \\
\hline Dry dep. land & 48 & 34 & 28 & 40 \\
\hline Dry dep. ocean & 56 & 49 & 48 & 101 \\
\hline Wet deposition & 3.6 & 3 & 2.7 & 13 \\
\hline Lifetime (days) & 5.8 & 5.8 & 5.7 & 4.7 \\
\hline Burden $(\mathrm{Tg})$ & 3.7 & 3.0 & 2.9 & 3.1 \\
\hline
\end{tabular}

Notes: ${ }^{a}$ refers to the sum of anthropogenic, biomass burning, and biofuel source, ${ }^{\mathrm{b}}$ : includes a plant growth source of $80 \mathrm{Tg}^{\mathrm{yr}}{ }^{-1}$ and a plant decay source of $23 \mathrm{Tg}$ yr $^{-1}$.

cycle simulation with a 20-min time step. The model is described thoroughly in a number of previous studies (Müller and Stavrakou, 2005; Stavrakou et al., 2009a,b).

Biogenic emissions of methanol are obtained either from the Jacob et al. (2005) inventory or by the MEGANv2.1 algorithm described in Sect. 2. Jacob et al. (2005) used net primary production and heterotrophic respiration to parameterize the plant growth and decay sources of methanol, with a total annual emission flux that is $44 \%$ higher than in MEGANv2.1 (151 vs. $104.7 \mathrm{Tg} \mathrm{yr}^{-1}$ ).
Global anthropogenic NMVOC emissions are obtained from the RETRO database for the year 2000 (http://retro. enes.org/data_emissions.shtml). Over Asia, RETRO is replaced by the REAS inventory for anthropogenic NMVOC emissions in 2009 (Ohara et al., 2007). Assuming that methanol represents $100 \%$ of alcohol emission in RETRO and $50 \%$ of the "other hydrocarbons" category in REAS, the global annual anthropogenic source of methanol (including biofuel use) amounts to $9.3 \mathrm{Tg} \mathrm{yr}^{-1}$. 
A priori (S1) $\mathrm{CH} 3 \mathrm{OH}$ column

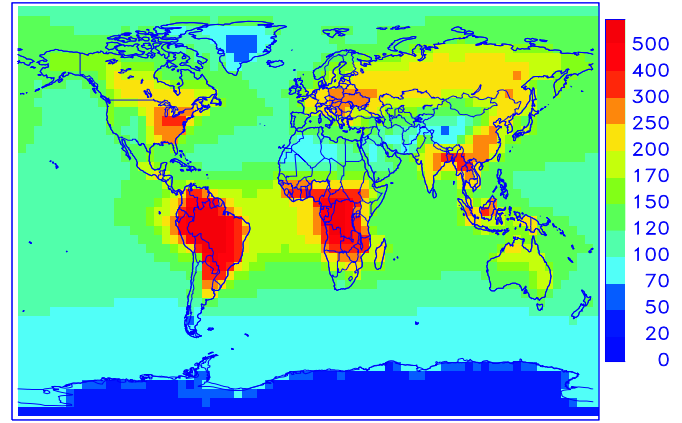

IASI CH3OH column

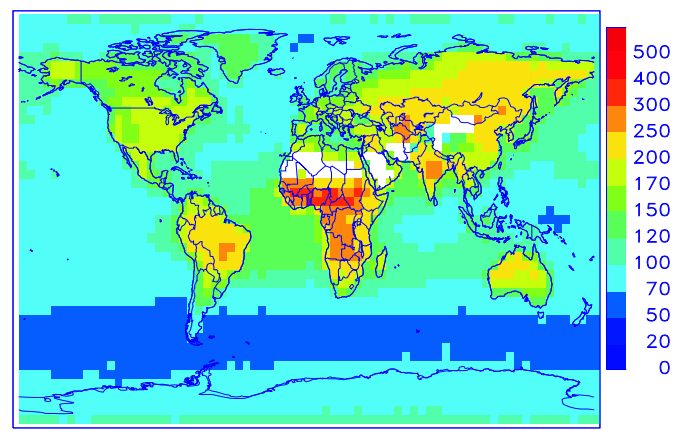

A priori (S2) $\mathrm{CH} 3 \mathrm{OH}$ column

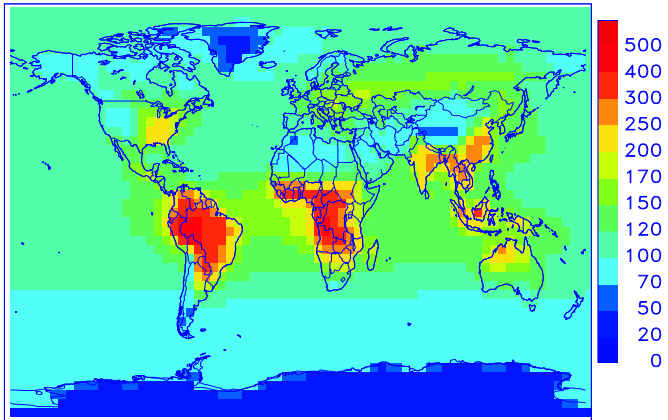

A posteriori (OptS2) $\mathrm{CH} 3 \mathrm{OH}$ column

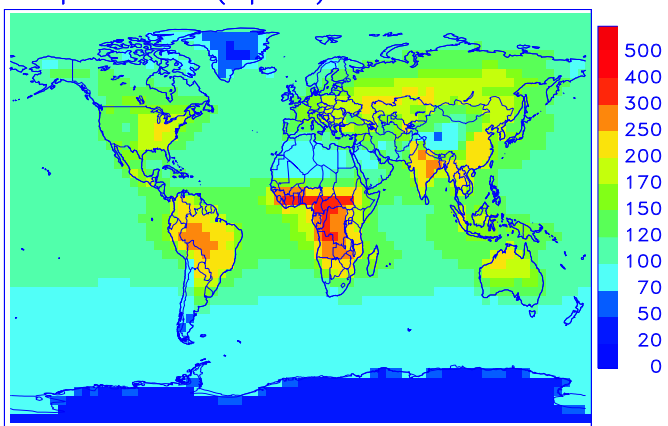

Fig. 3. Top panels: a priori global maps of annually averaged methanol columns simulated in S1 and S2 (Table 1). Bottom left: IASI yearly averaged methanol column abundances for 2009 gridded onto a $4^{\circ} \times 5^{\circ}$ horizontal resolution. Blanks correspond to regions where the quality of the retrievals might be doubtful, mainly due to emissivity problems (Razavi et al., 2011). Bottom right: methanol columns inferred from the OptS2 inversion study (Table 1). Units are $10^{14} \mathrm{~mol} \mathrm{~cm}^{-2}$. Note that modelled columns account for IASI averaging kernels.

Monthly vegetation fire emissions are obtained from the newly released version 3.1 of the Global Fire Emission Database (GFED, http://www.falw.vu/ gwerf/GFED/index. $\mathrm{html})$. This dataset comprises a distinction between emissions from savanna, woodland, and forest fires, agricultural waste burning, peatlands, deforestation and degradation fires (van der Werf et al., 2010). Trace gas emissions have been derived from carbon emissions using emission factors obtained from Andreae and Merlet (2001) with updates from M. O. Andreae, personal communication, 2007. The global methanol biomass burning flux is estimated at $5.3 \mathrm{Tg}$ in 2009 .

In the atmosphere methanol is formed through reactions of the methylperoxy radical $\left(\mathrm{CH}_{3} \mathrm{O}_{2}\right)$ with itself or through its reactions with other organic peroxy radicals. It is also formed through the photolysis of glycolaldehyde. The atmospheric production source in IMAGESv2 amounts to $31 \mathrm{Tg} \mathrm{yr}^{-1}$ globally, in good agreement with past modelling studies (Galbally and Kirstine, 2002; Jacob et al., 2005; Millet et al., 2008).

The global methanol emission amounts to $239 \mathrm{Tg} \mathrm{yr}^{-1}$ in the S1 simulation using the Jacob et al. (2005) emission model, and to $193 \mathrm{Tg} \mathrm{yr}^{-1}$ in S2 using the MEGANv2.1 source (Table 1).

More than half the atmospheric methanol is removed through $\mathrm{OH}-$ oxidation, the remainder through dry deposi- tion to land and ocean. Wet deposition contributes little to the global sink (Table 1). The dry deposition velocity of methanol to land is parameterized as a function of the leaf area index (LAI), obtained from the MODIS satellite for 2005 (Zhang et al., 2004). It is assumed to increase linearly from 0 to $0.75 \mathrm{~cm} \mathrm{~s}^{-1}$ when LAI increases from 0 to $6 \mathrm{~m}^{2} \mathrm{~m}^{-2}$. A comprehensive description for the wet scavenging parameterization used in IMAGESv2 is given in the Supplement of Stavrakou et al. (2009b). The Henry's Law coefficient used for methanol is equal to $5.8 \times 10^{-6} \exp (5200 / T)$ moll ${ }^{-1} \mathrm{~atm}^{-1}$ (Snider and Dawson, 1985; Sander, 1999). The global annual methanol budget is illustrated in Table 1 (first three columns), and simulated a priori methanol columns in S1 and S2 are illustrated in Fig. 3.

\section{Inversion constrained by IASI methanol columns}

\subsection{Methanol retrievals from IASI}

Launched in 2006, the IASI/MetOp-A nadir looking Fourier transform spectrometer probes the Earth's atmosphere in the thermal infrared spectral range. It has a $12-\mathrm{km}$ footprint diameter at nadir and is able to deliver two global earth coverages per day with a very good signal-to-noise ratio. The capabilities of IASI to measure the atmospheric composition 
are presented in a number of studies, e.g. Clerbaux et al. (2009); Coheur et al. (2009); George et al. (2009); Boynard et al. (2009). Recently, IASI has been used to derive global tropospheric methanol column distributions, as thoroughly described in Razavi et al. (2011). The retrieval method is briefly presented here.

The method applied to retrieve methanol column data is based on brightness - temperature differences $\left(\Delta T_{b}\right)$ between the target channel of $1033 \mathrm{~cm}^{-1}$, where the methanol absorption in the IASI spectra is the strongest, and contiguous baseline channels at 1019, 1019.5, 1036.25, 1038, 1047 and $1048.5 \mathrm{~cm}^{-1}$, where the methanol absorption is weak (Razavi et al., 2011). The method then consists in (i) determining global $\Delta T_{b}$ values, which provide qualitative information about the strength of the absorption, (ii) applying a correction in order to minimize the impact of ozone and water vapor, and (iii) converting $\Delta T_{b}$ to total columns through a radiative transfer model. To reduce computational cost, radiative transfer calculations have been performed over a limited number of world regions, and the conversion factors were derived by matching the retrieved columns on the corresponding $\Delta T_{b}$ over land and over ocean. They are applied to deduce total methanol column distributions on the global scale (Razavi et al., 2011). Only daytime (09:30 local time) clear sky scenes are considered in the retrieval and measurements above sand surfaces are filtered out because of emissivity spectral features. Currently, available products are monthly averages. The relative error on the retrieved monthly methanol column is estimated at approximately $50 \%$ over continents, although it can be higher in case of low thermal contrast and/or low signal-to-noise ratio. An absolute error of $10^{16} \mathrm{~mol} \mathrm{~cm}{ }^{-2}$ is therefore quadratically added to this constant relative error.

The annual methanol column abundances obtained from IASI for 2009 are illustrated in the bottom left panel of Fig. 3. The observed enhanced $\mathrm{CH}_{3} \mathrm{OH}$ columns $\left(>3 \times 10^{16} \mathrm{~mol} \mathrm{~cm}^{-2}\right)$ are associated with strong emissions from plants and vegetation fires, whereas very low columns are observed over the oceans.

The IMAGESv2 columns are compared with IASI column abundances in 2009 after a 4-month spin-up period starting on 1 September 2008. Mean averaging kernels (separated for land and ocean profiles) were used to account for the vertical sensitivity of the IASI instrument. This is an approximation as the vertical sensitivity is not constant and depends on the temperature and the type of surface. For instance, less information near the ground is usually acquired over ocean or forest surfaces. As shown in Razavi et al. (2011), the IASI total column averaging kernels peak between 5 and $10 \mathrm{~km}$ and are very broad, suggesting that IASI measurements are mostly sensitive to free to mid tropospheric columns. The seasonality of the IASI data is compared to the model seasonality for selected large world regions in Figs. 5 and 6. A discussion on these results follows in Sect. 7.

\subsection{Inverse modelling approach}

The inversion scheme used for deriving "top-down" methanol emission updates is based on the adjoint of IMAGESv2 (Müller and Stavrakou, 2005; Stavrakou and Müller, 2006), which has been used in earlier studies to infer emissions of reactive gases constrained by satellite data (Stavrakou et al., 2008, 2009b,c). The adjoint method is used to compute the derivatives of the cost function (misfit between the model and the observations)

$J(\mathbf{f})=\frac{1}{2}\left[(H(\mathbf{f})-\mathbf{y})^{T} \mathbf{E}^{-1}(H(\mathbf{f})-\mathbf{y})+\mathbf{f}^{T} \mathbf{B}^{-1} \mathbf{f}\right]$,

with respect to a number of control variables $\mathbf{f}$ (emission parameters) allowing to address problems involving a very large number of control variables, like grid-based inversions where fluxes are updated at every model grid cell. In Eq. (11) $H(\mathbf{f})$ is the model operator acting on the control variables, $\mathbf{y}$ is the observation vector, $\mathbf{E}, \mathbf{B}$ are the covariance matrices of the errors on the observations and the emission parameters $\mathbf{f}$, respectively, and ${ }^{T}$ is the transpose of the matrix. The cost function $J$ is minimized through an iterative descent algorithm which makes use of the forward and the adjoint model of IMAGESv2. A set of updated emission fluxes is determined after ca. 20 iterations (Stavrakou and Müller, 2006).

The methanol concentration in water $\left(C_{\mathrm{w}}\right.$, Eq. $(8)$ is taken equal to $7.1 \times 10^{13} \mathrm{~mol} \mathrm{~cm}^{-3}$, which corresponds to the mean

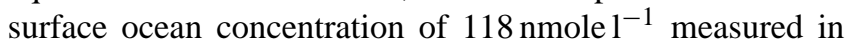
the tropical Atlantic (Williams et al., 2004).

Two emission categories are optimized, namely the pyrogenic and biogenic emissions, while anthropogenic and ocean emissions are kept at their a priori values (Table 1). The number of unknowns to be determined by the inversion is equal to ca. 15000 (5000 for biomass burning, 10000 for biogenic). The errors on the emission parameters, which are represented by the diagonal elements of the $\mathbf{B}$ matrix, are assumed to be a factor of two for biogenic emissions, and a factor of 2.5 for biomass burning. Spatial and temporal correlations are introduced in the inversion through the off-diagonal elements of the B matrix, as in Stavrakou et al. (2009c). The spatial correlations between errors on the emissions from two grid cells are assumed to decay exponentially with the distance $d$ between the grid cells, $e^{-d / \ell}$, with $\ell=500 \mathrm{~km}$ for both emission categories. Temporal correlations are assumed to decrease linearly between 0.25 for adjacent months and zero for a 6-month time lag.

The inversion study OptS2 (Table 1) is performed using MEGANv2.1 as a priori for plant emissions. The inversion is constrained by IASI columns over continents. Oceanic data are excluded from the inversion due to their large uncertainties. The inferred methanol budget is illustrated in Table 1 (fourth column) and annually averaged global maps of methanol columns are shown in Fig. 3. The derived annual ratio of the optimized to the prior source is illustrated 

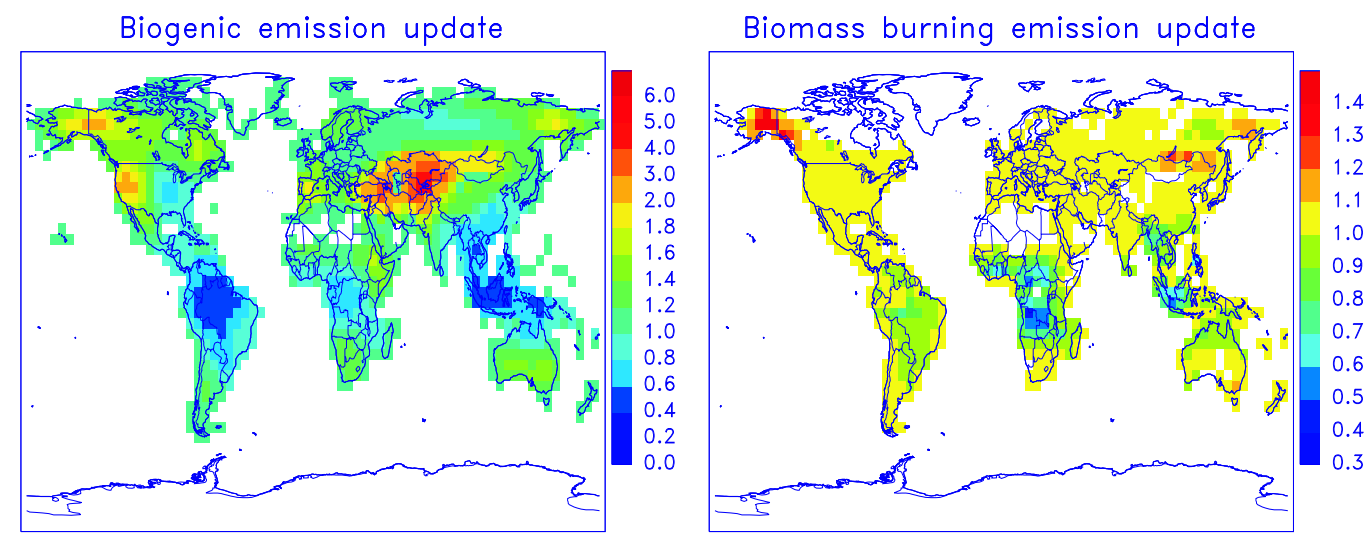

Fig. 4. Annual ratios of a posteriori to a priori biogenic (left) and biomass burning (right) emissions inferred by the OptS2 inversion study.
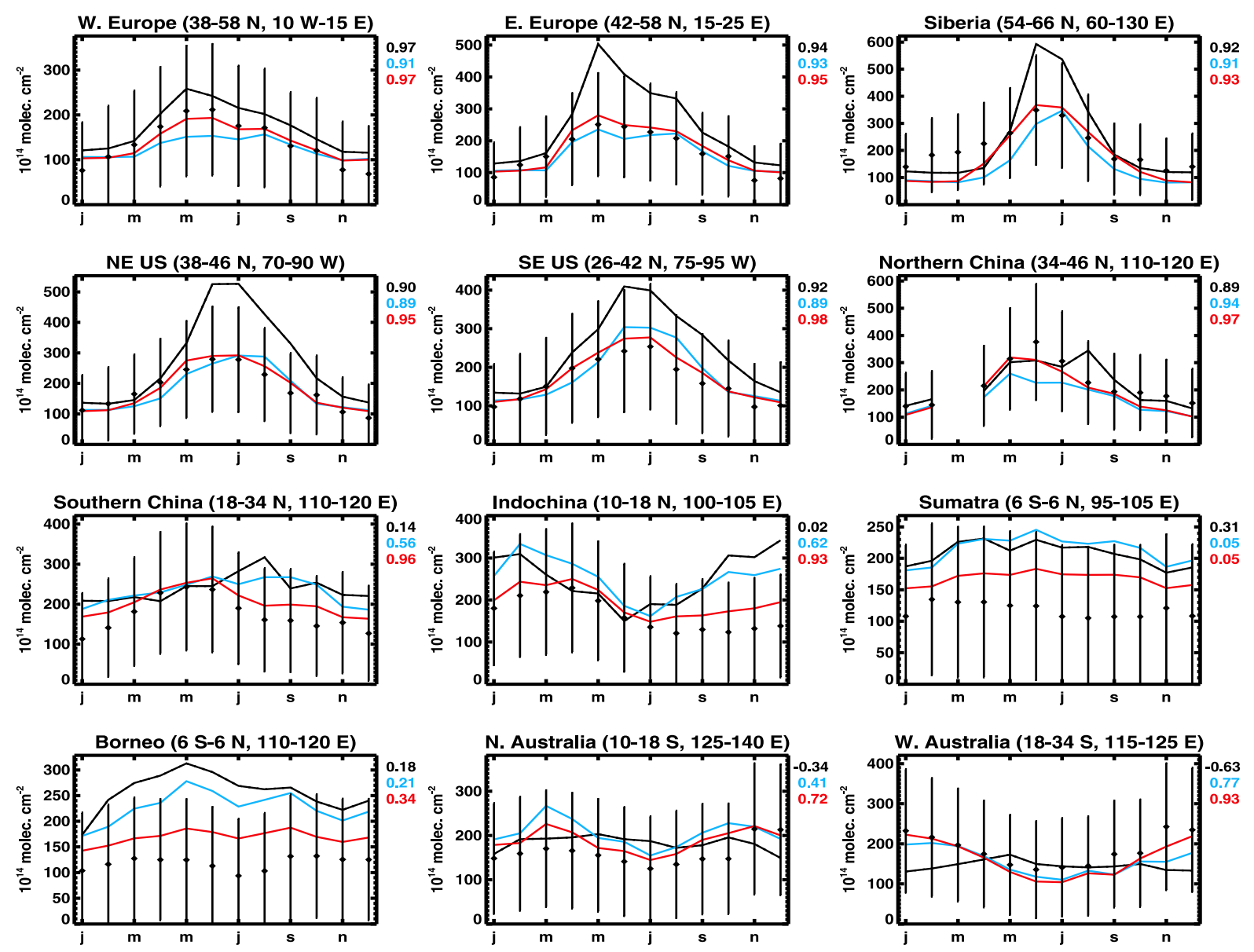

Fig. 5. Comparisons over selected regions between monthly averaged IASI methanol columns (black diamonds) with modelled columns of the S1 (black), S2 (blue), and OptS2 (red) simulations of Table 1. Numbers in the right end of each plot correspond to the correlation coefficients calculated for each simulation. 

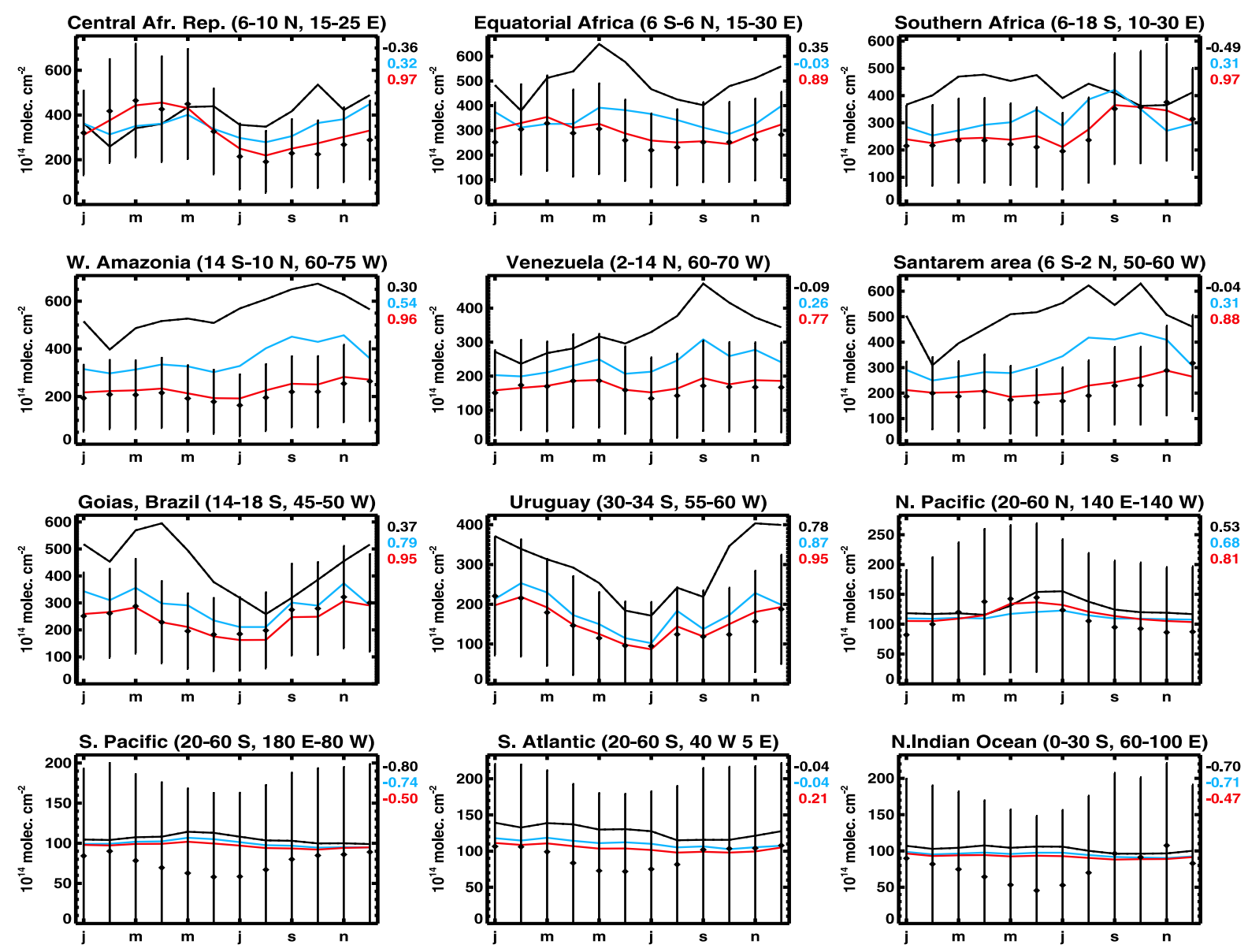

Fig. 6. As in Fig. 5 but for tropical and oceanic regions.

in Fig. 4 and the inferred regional changes in the biogenic source strength are summarized in Table 2.

\section{Independent methanol observations used for model evaluation}

\subsection{Airborne data}

Methanol distributions obtained from different aircraft field campaigns are used to evaluate the model predictive skills for methanol concentrations. More specifically we use:

1. The INTEX-A (Intercontinental Chemical Transport Experiment - North America) mission conducted in the summer of 2004 (1 July to 15 August 2004) over North America and the Atlantic aboard a DC-8 aircraft platform. The plane flew from the US west coast, over the Pacific, moved to mid-America, the Eastern US coast, and the north western Atlantic. The data and flight tracks are available via the NASA INTEX-NA archive (ftp://ftp-air.larc.nasa.gov) and an overview of the mission is provided in Singh et al. (2006).
Table 2. Biogenic emission estimates of methanol (in $\mathrm{Tg} \mathrm{yr}^{-1}$ ) in large world regions before and after optimization.

\begin{tabular}{lrr}
\hline Regions & S2 & OptS2 \\
\hline Europe & 6.1 & 8.2 \\
North America & 13.2 & 15.2 \\
South America & 27.4 & 18.0 \\
Northern Africa & 14.2 & 14.3 \\
Southern Africa & 12.6 & 11.7 \\
South Asia & 16.2 & 14.0 \\
\hline Global & 104.7 & 100 \\
\hline
\end{tabular}

2. The NOAA WP-3D aircraft platform employed during the NEAQS-ITCT (New England Air Quality Study Intercontinental Transport and Chemical Transformation) study. The methanol measurements have been obtained between 5 July to 15 August 2004 using a PTR-MS (Proton Transfer Reaction Mass Spectrometer) instrument over the region of the Ohio Valley, the 

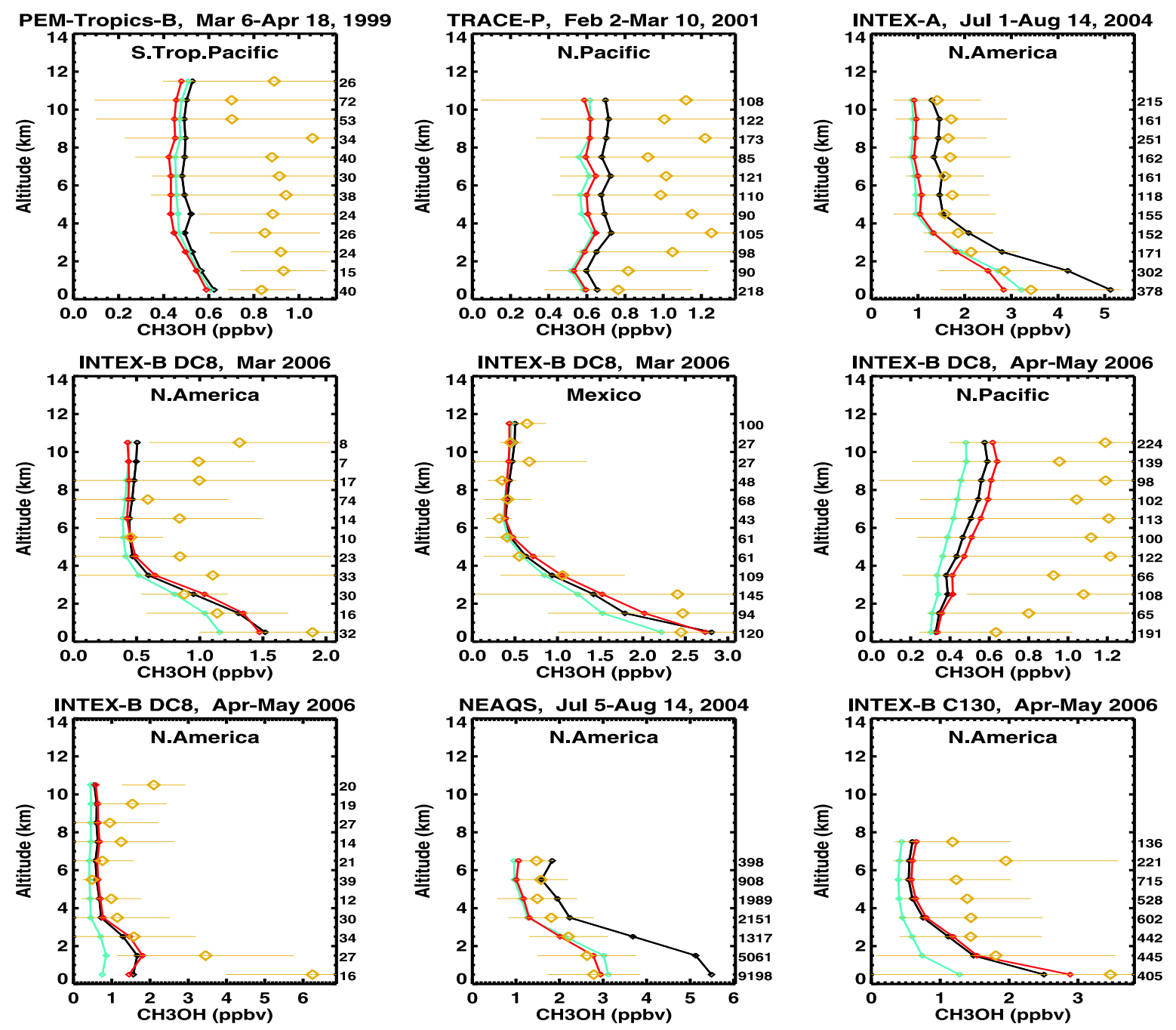

Fig. 7. Mean simulated (for 2009) and observed vertical distributions of methanol concentrations during the INTEX-A, NEAQS, INTEX-B, PEM-Tropics-B and TRACE-A aircraft campaigns. Regions are: North America $\left(25-55^{\circ} \mathrm{N}, 45-130^{\circ} \mathrm{W}\right), \mathrm{Mexico}^{\circ}\left(0-25^{\circ} \mathrm{N}, 85-110^{\circ} \mathrm{W}\right)$, N. Pacific $\left(25-55^{\circ} \mathrm{N}, 160-230^{\circ} \mathrm{E}\right)$, South Tropical Pacific $\left(0-40^{\circ} \mathrm{S}, 180-275^{\circ} \mathrm{W}\right)$. Colored curves correspond to the simulations of Table 1 , black for S1, blue for S2, and red for the OptS2 inversion. The number of observations available at each altitude bin is given on the right end of each plot. Error bars are standard deviations.

eastern seaboard, New England and the North Atlantic (http://www.esrl.noaa.gov/csd/2004/p3platform.shtml).

3. The INTEX-B two-phase aircraft mission conducted in spring 2006 (1 March to 15 May) over the region of Mexico in March (first phase) and over the Pacific in April and May (second phase). Detailed information on this mission is provided at the INTEX-B web site (http://www.espo.nasa.gov/intex-b/index.html) and a large number of studies realized using INTEX-B measurements are included in Molina et al. (2010).

4. The PEM-Tropics B (Pacific Exploratory Mission in the central and eastern regions of the tropical Pacific Ocean basin) and TRACE-P (Transport and Chemical
Evolution over the Pacific) aircraft missions conducted in March-April 1999 and February-March 2001, respectively, as part of NASA's Global Tropospheric Experiment (GTE). Detailed information on these experiments can be found at the GTE page (http://www-gte. larc.nasa.gov/gte_fld.htm). The data, compiled onto a $5 \times 5$ degrees grid with a vertical resolution of $1 \mathrm{~km}$ by Emmons et al. (2000), can be accessed through the data composites web page (http://acd.ucar.edu/ emmons/ DATACOMP/camp_table.htm).

A compilation of in situ literature measurements of methanol concentrations is also used to evaluate the a priori and optimized model performance. Detailed descriptions of these data can be found in the references of Table 5. The data 

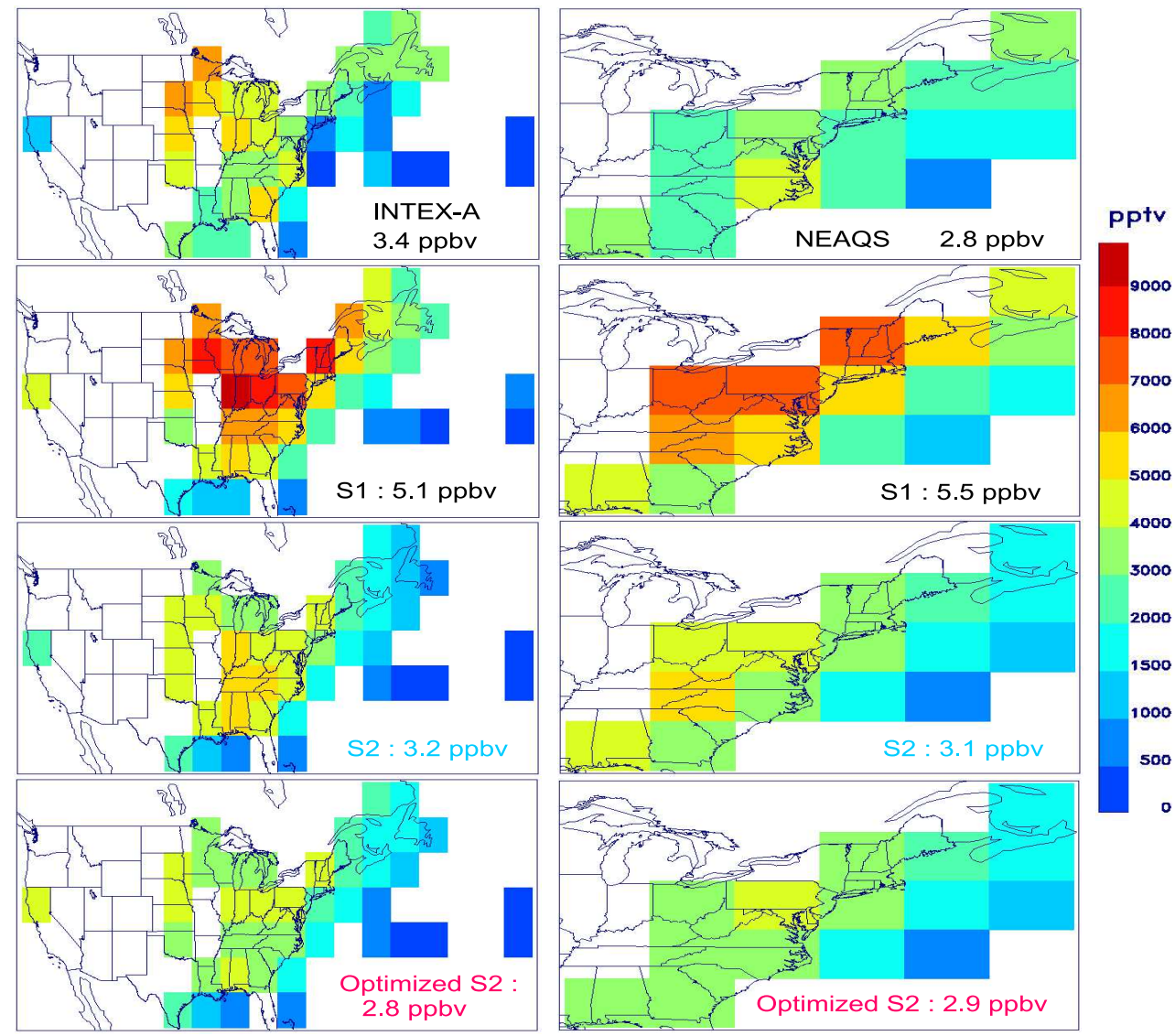

Fig. 8. Comparison between data from the INTEX-A and NEAQS campaigns and model concentrations from S1, S2 and OptS2 simulations averaged between the surface and the altitude of $1 \mathrm{~km}$. The mean methanol concentrations over the corresponding aircraft flight domains are provided inset.

are compared with modelled concentrations before and after the inversion averaged for the given measurement duration (Fig. 9). Besides these data, we also evaluate the model using recently retrieved methanol concentrations at a European forest site, and methanol total columns from FTIR (Fourier Transform Infrared) measurements at a southern tropical remote site in the Indian ocean. These datasets are briefly described below.

The Vielsalm measurement site is located in the Belgian Ardenne forest $\left(50.3^{\circ} \mathrm{N}, 6^{\circ} \mathrm{E}\right.$, altitude: $\left.450 \mathrm{~m}\right)$. This site has a mixture of coniferous species, mainly Douglas fir, Norway spruce, silver fir, and deciduous species, mainly beech. Long-term BVOC ecosystem-scale flux measurements were performed from a $52 \mathrm{~m}$ high tower by the disjunct eddycovariance technique (see e.g. Spirig et al., 2005) between 26 June and 16 November 2009, and from 25 March until 16 November 2010. A PTR-MS is used for on-line sensitive and fast BVOC concentration measurements. Monitored BVOC are formic and acetic acid, methanol, acetaldehyde, acetone, isoprene, sum of methyl vinyl ketone and methacrolein, $\mathrm{C}_{5}$ alcohols, and the sum of monoterpenes. A detailed descrip- tion of the experimental setup can be found in Laffineur et al. (2010). Comparisons of monthly averaged model concentrations in 2009 and measured concentrations between July and September 2009, and between April and September 2010 are shown in Fig. 10.

The FTIR instrument at the Reunion Island $\left(21^{\circ} \mathrm{S}, 55^{\circ} \mathrm{E}\right)$ is operating on a quasi-continuous basis since May 2009, whereas three campaigns have been conducted in previous years (Senten et al., 2008; Vigouroux et al., 2009). For this work we focus on the period between June and December 2009. The methanol retrievals are performed in the 1029$1037 \mathrm{~cm}^{-1}$ spectral range, in the region of the $v_{8} \mathrm{Q}$ branch (see also Beer et al., 2008; Coheur et al., 2009). Methanol vertical profiles at Reunion are retrieved using the inversion algorithm SFIT2 Rinsland et al., 1998 (v3.94), and using an a priori volume mixing ratio profile constant at $0.9 \mathrm{ppbv}$ below $12 \mathrm{~km}$, decreasing rapidly above this altitude to reach $0.1 \mathrm{ppbv}$ at $20 \mathrm{~km}$, in consistency with the PEM-Tropics-B aircraft mission (Fig. 7) and ACE-FTS measurements (Dufour et al., 2006). The retrieval is constrained by Tikhonov L1 regularization (Tikhonov, 1963) as in Vigouroux et al. 
South American sites

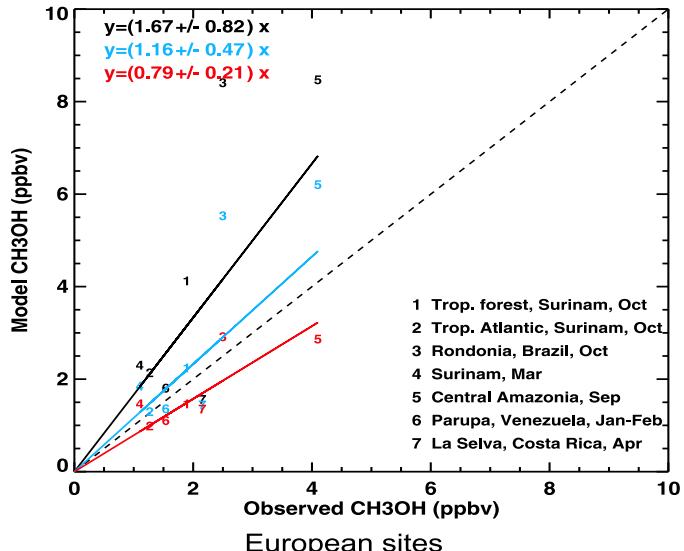

European sites

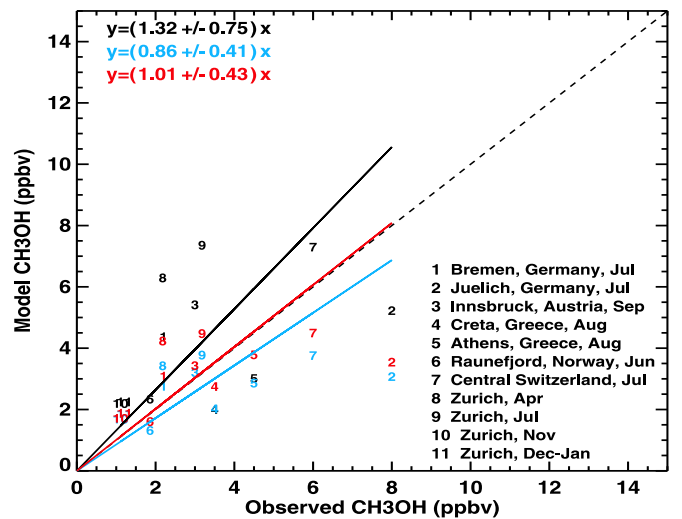

North American sites
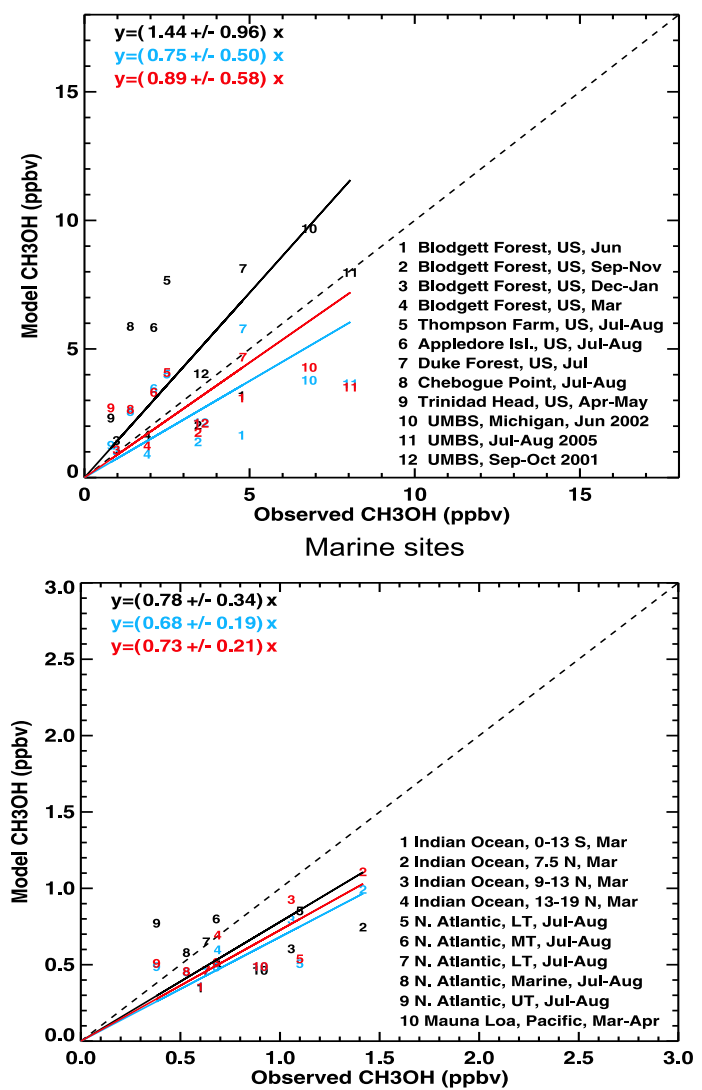

Fig. 9. In situ measurements of methanol concentrations shown on Table 5 are compared with the predicted concentrations from simulations S1 (in black), S2 (in blue) and OptS2 (in red). For each simulation, the slopes of the regression lines passing through the origin as well as their standard deviations are illustrated inset respecting the same color code.

(2009). Due to the low degree of freedom for the signal, only total columns are delivered. Monthly averaged model columns are compared with monthly averaged observations in Fig. 11.

\subsection{Surface-based data}

\section{A priori results - discussion}

The use of the NPP-based Jacob et al. (2005) a priori inventory in the $\mathrm{S} 1$ experiment leads to significantly higher methanol columns compared to those by the satellite over the majority of continental regions (Fig. 3). On an annual basis, the largest overestimation is found over Amazonia (factor of 2-3), and over Africa and Indonesia (factor of 1.5-2), whereas more moderate overestimations are observed over Europe, Northern America and Australia, and a good overall agreement is found over Siberia. In the S2 simulation, the model output lies closer to IASI data, despite persistent overestimations in the Tropics, which are nevertheless less significant compared to $\mathrm{S} 1$.
In Fig. 7 we present comparisons between the mean simulated (using S1, S2, and OptS2) and observed vertical profiles of methanol concentrations above large continental and oceanic regions. The model concentrations have been averaged over the same regions taking into account the location of the measurements. Comparisons between INTEX-A and NEAQS data and modelled concentrations below $1 \mathrm{~km}$ are shown in Fig. 8.

A model feature, not corroborated by the comparisons with IASI, is the important difference between methanol columns over eastern and western US (Fig. 3). Another common feature of both simulations is the strong model underestimation over Central Asia (factor of 3), as well as significant underestimations over Western US and Western Australia (up to a factor of 2), due to the very low methanol source estimated by both plant emission models in arid, semi-arid regions or short-grass steppe and limited cropland ecosystems. Supporting evidence for higher-than-predicted methanol concentrations is provided by INTEX-B mission measurements made aboard a C-130 aircraft in April-May 2006 above the westernmost US (Fig. 7). In this case the 


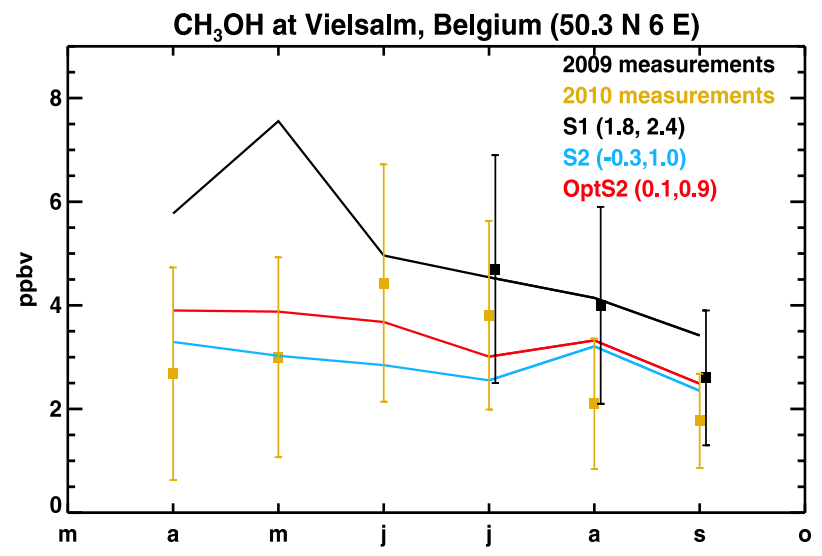

Fig. 10. Comparison between measured methanol concentrations near Vielsalm in Belgium (Table 5) and model results from the S1 (in black) and S2 (in blue) a priori simulations and from the OptS2 simulation (in red), see Table 1. Error bars correspond to the standard deviation. The average model/data bias and root mean square deviation are indicated inset in parentheses for each simulation.

model underprediction is, on average near the surface, similar to the one with IASI columns over the same region (factor of 2-3). Furthermore, long-term free tropospheric methanol measurements recorded at Kitt Peak Observatory $\left(31.9^{\circ} \mathrm{N}\right.$, $111.6^{\circ} \mathrm{W}$ ) between 2.09 and $14 \mathrm{~km}$ (Rinsland et al., 2009) corroborate the IASI measurements both in terms of magnitude and seasonality, showing a similar peak-to-trough amplitude of about 3 between winter and summer, as shown in Fig. 12. The model underestimates the Kitt Peak observed columns by almost a factor of two in summertime, and by $15 \%$ during winter, i.e. the seasonal variation is partly reproduced but is less pronounced. The model underestimation points to the existence of a larger-than-modelled biogenic methanol source in such ecosystems. Geron et al. (2006) investigated biogenic VOC emissions from common desert plants in the southwestern US. The study was focused on terpenoid emissions but some cut branches were analysed with a PTR-MS system so that emissions of methanol and other compounds could be investigated. They observed extremely high methanol rates, 100 to $250 \mathrm{\mu g} \mathrm{g}^{-1} \mathrm{~h}^{-1}$, which is several orders of magnitude higher than typically observed for other plant species. These high rates were attributed to the experimental approach of cutting branches and placing them in water in order to transport the branches for analysis. However, the process by which these plants were able to produce high methanol emission rates was not identified. More recently, Jardine et al. (2010) reported first in-situ measurements of methanol fluxes from a desert shrub, creosote bush, which is a dominant species in the North American Sonoran and Mojave deserts. The average $4.5 \mu \mathrm{g} \mathrm{g}^{-1} \mathrm{~h}^{-1}$ emission factor for creosote bush is more than a factor of two higher than the average emission factors of other trees and shrubs (see Harley et al. (2007) and literature reviewed by
Seco et al., 2007), although it is well within the range of these values. Extrapolating the Jardine et al. (2010) measurements to the canopy scale results in a MEGAN methanol emission factor of $\sim 2 \mathrm{mg} \mathrm{m}^{-2} \mathrm{~h}^{-1}$ for creosote bush, which is more than twice the value used for shrubs in MEGANv2.1. These limited enclosure measurements, along with the IASI satellite observations, suggest that the desert vegetation has a relatively high methanol emission capacity. Above canopy flux measurements are needed to verify this conclusion. The satellite columns remain, however, the only available source of information over Central Asia and western Australia, so that a similar multi-sensor-to-model comparison cannot be conducted.

The Jacob et al. (2005) biogenic emissions used in the S1 simulation lead to modelled methanol columns over northeastern US that are on average by $60 \%$ higher than IASI, while the overestimation reaches $90 \%$ in summertime (Fig. 5). This is consistent with the overestimation reported in Millet et al. (2008) with respect to aircraft observations over the US when the Jacob et al. (2005) plant emissions were used, which was attributed to a possible overestimation of the Galbally and Kirstine (2002) emission factors used to derive the Jacob et al. (2005) methanol emissions. Millet et al. (2008) found that halving the values for all plant functional types, or reducing the emission factors for broadleaf trees and crops by a factor of four, improved significantly the agreement with the observations. On the other hand, the use of MEGANv2.1 greatly improves the comparison wih the satellite data: the model overestimates by less than $10 \%$ in both Northeastern and Southeastern US over the entire year, although the overprediction reaches $28 \%$ in summertime southeastern US. Comparisons of S1 results with INTEX-A and NEAQS aircraft data (Sect. 6.1, Fig. 7) present also large overestimations in the boundary layer below $1 \mathrm{~km}$, by $50 \%$ and $95 \%$ for INTEX-A and NEAQS, respectively, while the S2 predicted concentrations agree with the measurements within $10 \%$ (Fig. 8). This result is corroborated by surface measurements at North American sites (most of them in Eastern US), shown in Table 5. As shown in Fig. 9, the $\mathrm{S} 1$ predicted concentrations yield a mean overestimation of $44 \%$ at these sites, whereas S2 underpredicts the measurements by ca. $10 \%$. However, in spite of the better overall model performance near the surface when $\mathrm{S} 2$ results are considered, comparisons of modelled to aircraft vertical profiles from INTEX-A, INTEX-B and NEAQS missions above North America show an important underestimation (up to $45 \%$ in the case INTEX-A) of methanol concentrations in the free troposphere (Fig. 7). The reasons for this behaviour are not completely clear and will be addressed in Sect. 10.

The comparisons with aircraft measurements and in situ measurements over ocean point to a general model underestimation over the oceans (Fig. 7, Table 5, Fig. 9), suggesting a more significant ocean source than the one considered in the model (Sect. 3) and/or to an overestimated ocean deposition sink. High concentrations over ocean have 
been also reported in earlier aircraft campaign measurements over the Pacific (Singh et al., 1995, 2001). Nevertheless, the model/IASI comparisons over the Pacific, Atlantic and Indian ocean do not confirm these conclusions (Fig. 6). The predicted columns turn out to be higher than IASI observations in almost all regions and months, and they exhibit almost no seasonal variation, as opposed to the observations. It should be noted, however, that the IASI signal over the oceans is weak and large errors are associated to the columns. This issue warrants further study and underscores the need for further measurements at remote oceanic sites.

The MEGANv2.1 inventory reproduces better the magnitude and seasonal variation of the observed columns in most regions. This is also reflected in the correlation coefficients given in Figs. 5 and 6. In Indonesia, the S2 model overprediction with respect to IASI columns (factor of 2, Fig. 5) is in line with comparisons between modelled and observed methanol concentrations obtained during the OP3 campaign conducted in 2008 in the Malaysian rainforest during the wet (April-May) and early dry season (June-July) (Langford et al., 2010). More specifically, the S2 methanol concentrations calculated at the model grid cell comprising the campaign site located in northeastern Borneo $\left(5^{\circ} \mathrm{N}, 118^{\circ} \mathrm{E}\right)$ are 2.5 times higher than the concentrations of $1.2 \pm 0.46 \mathrm{ppbv}$, and $1.5 \pm 0.67 \mathrm{ppbv}$ observed in the wet and dry season, respectively. This finding could be partly explained by an overestimation of the methanol emission rate assumed in MEGANv2.1 for broadleaf forests ( $400 \mu \mathrm{g} \mathrm{m}^{-2} \mathrm{~h}^{-1}$, Sect. 2.2). In fact, flux measurements of methanol reported in Langford et al. (2010) at this rainforest site have a mean value very close to zero and a large variability $\left(-33 \pm 300 \mu \mathrm{g} \mathrm{m}^{-2} \mathrm{~h}^{-1}\right)$, suggesting that dry deposition plays an important role. Furthermore, these fluxes over Borneo are much lower than the net fluxes measured in the Amazon rainforest by Karl et al. (2004) $\left(500 \mu \mathrm{g} \mathrm{m}^{-2} \mathrm{~h}^{-1}\right)$. Such considerable discrepancies make evident that large variability is associated to measured fluxes even for relatively similar rainforest biomes, and therefore, the use of a single flux value for all broadleaf trees in MEGANv2.1 cannot be but a crude estimate. In Amazonia, the S2 model overestimation with regard to IASI reaches up to 50-70\% depending on the region (Fig. 6), but it is much more significant in the $\mathrm{S} 1$ simulation, in line with the findings of Millet et al. (2008). The use of MEGANv2.1 produces a nice agreement with IASI over the Goias province in central Brazil, a region of Brazil covered with woodland savanna, and Uruguay, mainly covered with tall prairie grass plains, lending confidence to the assumed methanol rates for grasslands in MEGANv2.1 (Fig. 6).

Above Africa and Australia, the comparisons of the S2 results with the IASI columns yield a satisfactory agreement both in terms of amplitude and seasonality, whereas the S1 simulation falls short of capturing the observed variations in the columns, as indicated by the negative calculated correlation coefficients. This suggests that the representation of methanol emissions based on net primary production as in Ja-

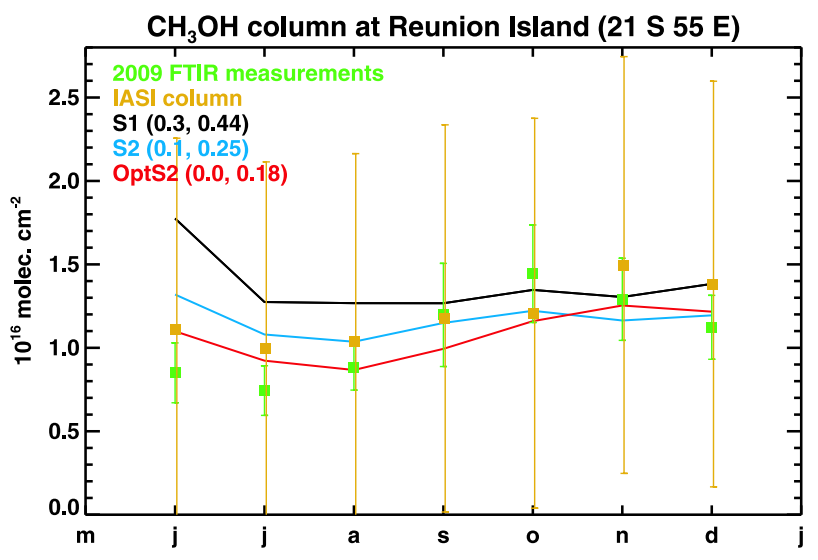

Fig. 11. Comparison between FTIR methanol columns at Reunion Island and model results from the S1 (in black) and S2 (in blue) a priori simulations and from the OptS2 simulation (in red), see Table 1. Green and orange error bars correspond to the standard deviation of FTIR measurements and the assumed error on IASI columns, respectively. The average model/FTIR bias and root mean square deviation are indicated inset in parentheses for each simulation.

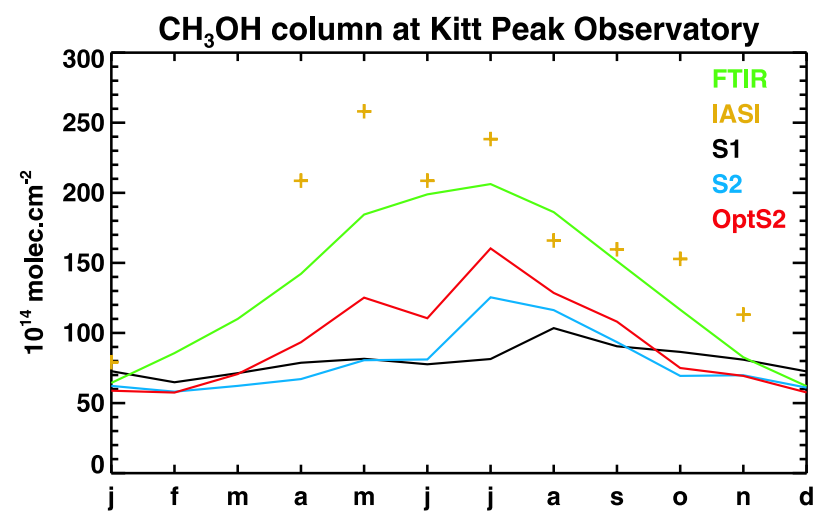

Fig. 12. Comparison between (1) monthly averaged FTIR data obtained at the Kitt Peak Observatory $\left(31.9^{\circ} \mathrm{N}, 111.6^{\circ} \mathrm{W}, 2.09-\right.$ $\mathrm{km}$ a.s.1.) with a 1-m Fourier transform spectrometer between October 1981 and December 2003 (Rinsland et al., 2009) (in green), (2) IASI columns (in orange), (3) columns simulated by S1, S2 and OptS2 between 2.04 and $14 \mathrm{~km}$. The total uncertainty in the 2.0914-km FTIR methanol columns due to both random and systematic errors is estimated at less than $20 \%$ (Rinsland et al., 2009). The correlation coefficient between the model and the FTIR data is equal to 0.55 in S1, 0.8 in S2, and 0.94 in OptS2 inversion.

cob et al. (2005) might not be adequate for tropical regions, both in terms of seasonality and magnitude. Over Europe, the S2 run results in a moderate underestimation and to a less marked seasonal cycle compared to IASI (Fig. 5). 


\section{Inversion results - discussion}

The global a posteriori biogenic methanol source deduced from the inversion amounts to $100 \mathrm{Tg} \mathrm{yr}^{-1}(\mathrm{OptS} 2$, Table 1) and is very close to the S2 a priori estimate. After optimization, the cost function (Eq. 11) is reduced by a factor of 2.1 globally and its gradient is reduced by a factor of 1200 . The optimization yields a significantly better agreement between the model and IASI data, which is carried through substantial changes in the biogenic and biomass burning emission fluxes, as shown in Figs. 3, and 4. Considerable changes of the biogenic source with regard to the a priori MEGANv2.1 database are recorded above Amazonia and Indonesia, with inferred annual reductions of $40-55 \%$ and $45-58 \%$, respectively, whereas significant reductions are also derived in the Eastern US (20-25\%) and Central Africa (25-35\%). Very significant increases of the biogenic source are deduced above Central Asia (up to a factor of 5), Western US (factor of 2), and the Iberian peninsula (ca. 90\%) (cf. Sect. 7). On the other hand, the methanol source from vegetation fires, although much less significant on the global scale compared to the biogenic source, is also strongly modified by the inversion, with inferred reductions of $35 \%$ above Indonesia, up to $38 \%$ above the Central African Republic, and up to $50 \%$ above Southern Congo.

Note that there might be some conflation of the biogenic and biomass burning source categories, due to the spatiotemporal coexistence of the two sources. However, the simultaneous optimization of two source categories is facilitated by the prescribed spatiotemporal correlations of the a priori errors (B matrix in Eq. 11), which tend to preserve the spatiotemporal patterns of the a priori emissions in each category. More importantly, at most locations/times, one of the two sources is largely dominant, and is therefore well constrained by the observations. For example, over Alaska, the large pyrogenic emission increases (Fig. 4) are due to fires in July/August 2009, resulting in methanol emissions about an order of magnitude larger than the biogenic emissions in that region. Conversely, the biogenic emission increases seen in Fig. 4 over Alaska and Yukon are mostly due to a strong enhancement in May-June, when biomass burning emissions are negligible.

Although the reduced plant emissions over the tropical Amazon allow for a very good match with the satellite observations, they lead to model underprediction of about $20 \%$ at 5 of the 7 sites located in South America (Table 5, Fig. 9, red line). The limited set of surface data over this region and the dearth of measurements from other platforms do not allow to draw further conclusions. It is however possible that IASI retrieved columns are low-biased over the tropical Amazon. One tentative explanation is the enhanced presence of clouds in this region. Even though all IASI data is cloud filtered prior to retrieval using the EUMETSAT level 2 data, completely cloud free scenes are extremely rare over tropi- cal rainforests. It is therefore not unlikely that residual cloud contamination is much larger in this region than in other parts of the world, resulting in lower observed methanol columns. This may also apply to tropical Africa or Asia. Over Indonesia, the emission decreases suggested by IASI bring the model much closer to the OP3 campaign measurements (Sect. 7), i.e. the initial overestimation is reduced from $250 \%$ to approx. $50 \%$.

Over the Eastern US, the optimized mixing ratios are in good agreement with both INTEX-A and NEAQS campaign measurements below $2 \mathrm{~km}$ (Figs. 7, 8). However, a significant underestimation remains in the free troposphere. This is not totally unexpected due to the likely effect of eastward transport from the Western US, where the modelled columns remain underestimated (Figs. 3, 12). In addition, sensitivity calculations indicate that an underestimation of convective fluxes and/or an overestimation of $\mathrm{OH}$ simulated concentrations could also partly explain the overestimated methanol gradient between the PBL and the free troposphere (see Sect. 10). The comparison at the marine sites shown in Table 5 is not improved after inversion (Fig. 9). Further, the optimized model concentrations calculated at the North American locations of Table 5 are now, on average, closer to the surface data, although the scatter is still significant (Fig. 9).

Plant emissions in Europe are increased on an annual basis by $35 \%$ (Table 2), with the most important increase found in Spain and Portugal. Further, comparison of the model concentrations from S1, S2 and OptS2 at the Vielsalm forested site (Fig. 10) shows that neither simulation succeeds in representing adequately the seasonality of the surface data. However, in terms of mean bias and root mean square deviation, the optimized results perform significantly better. Furthermore, the OptS2 simulation results in better agreement with the surface observations at different European sites, as depicted in Fig. 9, implying a reasonable consistency between satellite observations and ground-based measurements.

The IASI-derived decreases in pyrogenic and biogenic emissions over the central and Southern Africa are supported by the FTIR columns retrieved at the Reunion Island (Fig. 11). This site, located near Madagascar at a distance of about $2000 \mathrm{~km}$ from the continent, is influenced by longrange transport from continental air, given the relatively long methanol lifetime. The presence of strong biogenic emissions throughout the year in Southern Africa and the occurrence of important fire events from June to November have a significant impact on the observed methanol at this site. The inversion suggests reductions to both emission sources in almost all months except in November, when IASI column is at its highest. The observed seasonality is well reproduced by the model, which is also reflected in the low bias and root mean square deviations between the model and the observations.

Finally, the MEGANv2.1 and the optimized global biogenic source are found to be in line with the reported value 
by Millet et al. (2008) (Table 1), which was constrained by aircraft data, and are significantly lower compared to the Jacob et al. (2005) source. In opposition to these findings, a strong increase with respect to the Jacob et al. (2005) emissions was invoked by Dufour et al. (2007) during spring and summer in the Northern Hemisphere in order to explain the large mixing ratios sampled over high-latitude regions between 6 and $14 \mathrm{~km}$ by the ACE-FTS sensor. Although our model is also found to underpredict methanol concentrations in the free troposphere during the INTEX-A and NEAQS missions (Fig. 7), as well as over the Northern Atlantic (not shown), lower biogenic emissions are supported by both surface and aircraft measurements in the boundary layer. As discussed above, this underestimation might have multiple causes (cf. Sect. 10).

\section{A posteriori error estimation}

The errors on the a posteriori emission estimates are calculated by applying an off-line iterative approximation of the inverse Hessian matrix, which relies on the DavidonFletcher-Powell (DFP) updating formula (Fletcher, 1990). When assuming that the model is linear or not too far from being linear, the a posteriori error covariance matrix is related to the Hessian of the cost function $J$ through the expression:

$E_{\text {post }}=\left[(\mathbf{D H})_{f}^{T} \mathbf{E}^{-1}(\mathbf{D H})_{f}+\mathbf{B}^{-1}\right]^{-1}=(\mathbf{I H})_{f}$,

where $(\mathbf{I H})_{f}$ is the inverse Hessian matrix evaluated at the point $f,(\mathbf{I H})_{f}=\mathbf{H e s s i a n}(J)_{f}^{-1}, \mathbf{D H}$ is the Jacobian matrix of the model, and $\mathbf{E}$ and $\mathbf{B}$ are as in Eq. 11 (see Müller and Stavrakou (2005) for details). The inverse Hessian matrix is estimated iteratively using the new information obtained at each step $k$ of the minimization procedure through the DFP formula :

$(\mathbf{I H})_{k+1}=(\mathbf{I H})_{k}+\frac{s_{k} s_{k}^{T}}{y_{k}^{T} s_{k}}-\frac{(\mathbf{I H})_{k} y_{k} y_{k}^{T}(\mathbf{I H})_{k}}{y_{k}^{T}(\mathbf{I H})_{k} y_{k}}$,

where $s_{k}=f_{k+1}-f_{k}, y_{k}=(\nabla J)_{f_{k+1}}-(\nabla J)_{f_{k}},(\nabla J)_{f_{k}}$ is the gradient of $J$ at the point $f_{k}$, and the initial inverse Hessian matrix is taken to be equal to $\mathbf{B}$. by recursive application of the DFP updating formula to the vectors $f_{k}$ and $(\nabla J)_{f_{k}}$ calculated by the minimization algorithm (Sect. 5.2), we obtain an approximate inverse Hessian matrix. The square root of the diagonal elements of this matrix are the standard errors associated to the optimized parameter vector $\mathbf{f}$. The error reductions, i.e. the ratio of the a priori to the a posteriori errors are given in Table 4 for large continental regions. The largest error reductions are achieved for the biogenic source over regions where forests are dominant, like South America and the Former Soviet Union, where the a posteriori uncertainties are reduced by $50 \%$ and $67 \%$, respectively. Significant reductions are also found over Europe (40\%) and North America $(35 \%)$. The error on the biogenic source is decreased globally by $43 \%$. Because the biomass burning source represents only $3 \%$ of the global methanol source, the fire impact of the methanol levels is masked by the contribution of the biogenic source. Lower error reductions are therefore calculated for the vegetation fire source: of the order of $14 \%$ on the global scale, 10-12\% over Africa and southern Asia, and almost negligible error reductions over other regions.

Note that besides the DFP update formula, the BFGS formula (Broyden-Fletcher-Goldfarb-Shanno) for calculating the inverse Hessian matrix is widely used in large-scale problems (Fletcher, 1990). Both expressions have been evaluated against the finite difference approach in Müller and Stavrakou (2005). Applied to the OptS2 inversion results, the BFGS formula is found to yield results quite similar to those obtained with the DFP method.

\section{Sensitivity inversions}

Besides the uncertainties on the a posteriori emission fluxes calculated in the previous section, model errors lead to potentially significant uncertainties on the derived methanol fluxes, which are however very difficult to estimate. In this section we propose a tentative assessment of these errors, based on a set of sensitivity inversions conducted to investigate the influence of uncertainties on meteorological parameters, on methanol sink processes, and on the a priori methanol plant emission source. Although this evaluation is not exhaustive, it accounts for the most important uncertainties associated to the model. Table 3 summarizes the performed inversions and provides the corresponding tropical $\left(25^{\circ} \mathrm{S}\right.$ $25^{\circ} \mathrm{N}$ ), extratropical and global biogenic source inferred in each case study.

In the OptS2-conv inversion a factor of two increase in the convective updraft fluxes used in the model is assumed. Stronger convection leads to a redistribution of trace gases from the boundary layer upwards in the free troposphere, in regions with generally higher horizontal winds resulting in a stronger dispersion and lower methanol columns over source regions. In tropical regions, however, where horizontal winds are weak, this decrease is more than compensated by an increase in the modelled methanol columns calculated with the IASI averaging kernels, because of the higher sensitivity of the retrievals to the higher tropospheric layers. Regionally, the annual biogenic emission change inferred by OptS2-conv lies within $10 \%$ of the standard inversion (Fig. 13), whereas on the global scale the a posteriori biogenic source stays very close to that of the standard inversion. The largest emission changes are found over Amazonia, where about 10\% lower emissions are required to match the IASI columns when convection is enhanced. As expected, the a posteriori column changes are very small (less than $2 \%$ ) over source regions, due to the observational constraint. Enhanced transport from source regions to remote areas leads to small methanol column increases over oceans and deserts (Fig. 13). Comparison with the INTEX-A and NEAQS vertical profiles (Fig. 14, 
Table 3. Performed sensitivity inversions, and corresponding tropical, extratropical and global biogenic methanol source expressed

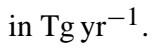

\begin{tabular}{|c|c|c|c|c|}
\hline Description & Name & Global & Tropical & Extra-tropical \\
\hline Standard & OptS2 & 100 & 62 & 38 \\
\hline Double convective fluxes & OptS2-conv & 99.4 & 61.2 & 38.2 \\
\hline $\begin{array}{l}\text { Methanol dep. velocity } \\
\text { increased by } 60 \% \\
\text { OH concentrations from }\end{array}$ & OptS2-drydep & 112 & 69 & 43 \\
\hline $\begin{array}{l}\text { Spivakovsky et al. (1990) } \\
\text { Use Jacob et al. (2005) }\end{array}$ & OptS2-OH & 91.5 & 59.5 & 32 \\
\hline a priori source & OptS1 & 103.8 & 62.4 & 42.4 \\
\hline
\end{tabular}

Table 4. Error reduction (ratio of the a priori to the a posteriori error) achieved by the OptS2 optimization calculated annually per source category and region.

\begin{tabular}{lrr}
\hline Regions & Biogenic & $\begin{array}{r}\text { Biomass } \\
\text { burning }\end{array}$ \\
\hline North America & 1.54 & 1 \\
South America & 2.10 & 1.06 \\
Northern Africa & 1.13 & 1.11 \\
Southern Africa & 1.08 & 1.10 \\
South Asia & 1.18 & 1.13 \\
Far East & 1.15 & 1 \\
Europe & 1.64 & 1 \\
FSU & 3.00 & 1.03 \\
Global & 1.74 & 1.16 \\
\hline
\end{tabular}

blue) indicates that a stronger convection improves the model profile over the US and leads to higher methanol concentrations in the free troposphere, in better agreement with the observations.

Motivated from recent findings by Karl et al. (2010) suggesting that the removal of oVOCs (oxygenated volatile organic compounds) by dry deposition might be substantially larger than is currently assumed for deciduous ecosystems, owing to their possible loss upon entering leaves through stomata, we carried out an inversion exercise where methanol deposition velocity is increased by $60 \%$ compared to the standard case. For example, the daily averaged deposition velocity for a leaf area index of $6 \mathrm{~m}^{2} \mathrm{~m}^{-2}$ is therefore assumed equal to $1.2 \mathrm{~cm} \mathrm{~s}^{-1}$. Note however that deposition processes for methanol and other oVOCs might be more complex, due to their water solubility and to the potential influence of an aqueous reservoir at the leaf-air interface in humid conditions. An improved representation of oVOC dry deposition will be the subject of further investigations. Due to the larger methanol sink in inversion Opt-drydep, the inferred global biogenic emission fluxes are $12 \%$ higher than in OptS2, but locally, especially over tropical forests, increases of up to $30 \%$ are found. The total column changes are generally negative, due to the influence of the a priori on the inversion, but always very weak (Fig. 13).

Another important removal process for methanol is the oxidation by $\mathrm{OH}$. By using the prescribed climatological $\mathrm{OH}$ fields by Spivakovsky et al. (1990), the OptS2-OH sensitivity inversion acknowledges the large uncertainties that currently exist on modelled $\mathrm{OH}$ concentrations, especially over tropical forests, and also in mid-latitude continental regions (Lelieveld et al., 2008; Ren et al., 2008; Hofzumahaus et al., 2009). Note that the Spivakovsky et al. (1990) parameterization ignores completely the depleting effect of isoprene and other biogenic VOC emissions on $\mathrm{OH}$, and therefore might overestimate the $\mathrm{OH}$ concentrations over forested areas, whereas isoprene emissions strongly deplete $\mathrm{OH}$ levels in IMAGESv2 despite the $\mathrm{OH}$ regeneration included in the MIM2+ mechanism used by the model, leading to substantial $\mathrm{OH}$ underestimations against campaign measurements over Amazonia and in the Eastern US (Stavrakou et al., 2010). The inferred emission changes, illustrated in Figure 13, reflect directly the differences between the modelled and the prescribed $\mathrm{OH}$ fields. In particular, moderate changes in the biogenic emissions are derived over Amazonia, Europe and US (less than 10\%), whereas decreases of up to $30 \%$ are found over central and south Asia. The lower OH concentrations of Spivakovsky et al. (1990) compared to IMAGESv2 at northern mid-latitudes lead to increased methanol lifetime, and consequently, to lower emission fluxes required to match the observations, as also reflected in the weaker vertical gradient of methanol mixing ratios over the US (Fig. 14, red line). Methanol is also more efficiently exported from midlatitude emitting regions strongly constrained by IASI data, to oceanic or desertic regions where the methanol columns are low and weakly constrained by the observations, as testified by the column increases shown in Fig. 13. The global plant emission is estimated to $91.5 \mathrm{Tg} \mathrm{yr}^{-1}$, i.e. by $8 \%$ lower than in the standard case, the decrease being more significant in the extratropics (Table 3).

Finally, in order to assess the influence of the a priori methanol plant emission inventory, we carried out the OptS1 inversion which uses the Jacob et al. (2005) inventory. The 

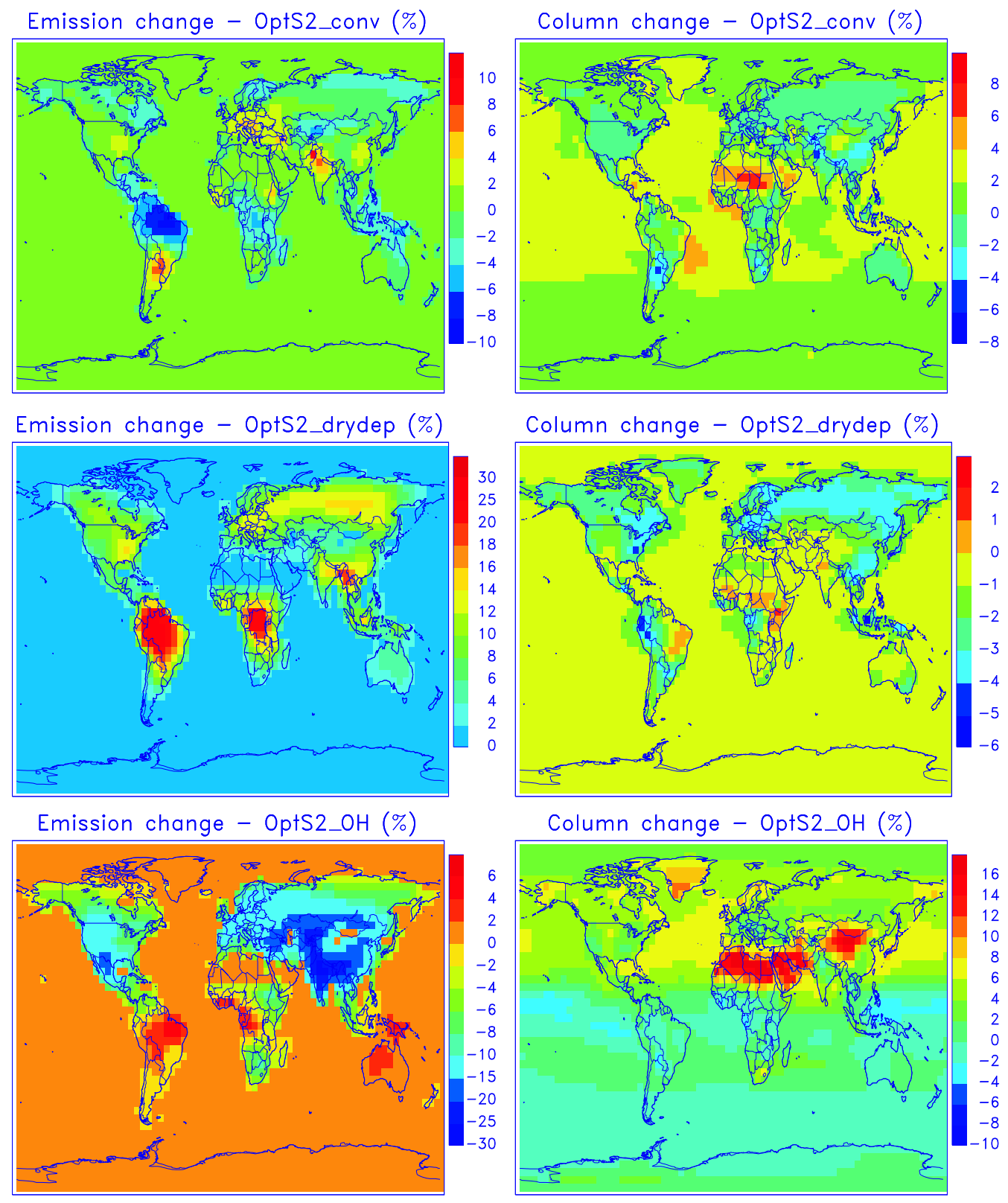

Fig. 13. Annual changes of the biogenic methanol emission (left) and methanol total column (right) derived from the three sensitivity inversions, OptS2-conv, OptS2-drydep, and OptS2-OH, described in Table 3, with respect to the standard OptS2 inversion.

results are found to be only moderately different from those deduced with the standard OptS2 inversion (Fig. 15, Table 3). Overall, the inferred emission estimates are found to be quite robust in the different sensitivity cases, with global estimates differing by less than $10 \%$, although differences of the order of $30 \%$ are found on the regional scale.

\section{Conclusions}

We have introduced a new model (MEGANv2.1) for estimating methanol emissions from the terrestrial biosphere, which is based on net ecosystem flux measurements and accounts for the influence of light, temperature, and leaf age. The MEGANv2.1 methanol emissions and a previous inventory by Jacob et al. (2005) have been used as a priori biogenic emissions in the IMAGESv2 global CTM and compared against multi-sensor methanol measurements. Besides ground-based and airborne methanol observations, a com- 
Table 5. In situ methanol measurements expressed in pptv.

\begin{tabular}{|c|c|c|c|c|}
\hline Location & Period & $\begin{array}{l}\text { Coordinates } \\
\text { Shape South America }\end{array}$ & $\mathrm{CH}_{3} \mathrm{OH}$ & Reference \\
\hline Surinam rainforest & Mar 1998 & $2-5^{\circ} \mathrm{N} 303-306^{\circ} \mathrm{E}$ & 1100 & Williams et al. (2001) \\
\hline Parupa, Venezuela & Jan-Feb 1999 & $5.7^{\circ} \mathrm{N} 298.2^{\circ} \mathrm{E}$ & 1540 & Sanhueza et al. (2001) \\
\hline Rondonia, Brazil & Oct 1999 & $10.1^{\circ} \mathrm{S} 297.1^{\circ} \mathrm{E}$ & 2500 & Kesselmeier et al. (2002) \\
\hline La Selva, Costa Rica & Apr-May 2003 & $10.4^{\circ} \mathrm{N} 276.1^{\circ} \mathrm{E}$ & 2155 & Karl et al. (2004) \\
\hline Central Amazonia & Sep 2004 & $2.6^{\circ} \mathrm{S} 299.8^{\circ} \mathrm{E}$ & 4100 & Karl et al. (2007) \\
\hline Trop. forest, Surinam & Oct 2005 & $4.5^{\circ} \mathrm{N} 305.0^{\circ} \mathrm{E}$ & 1890 & Lelieveld et al. (2008) \\
\hline \multirow[t]{2}{*}{ Trop. Atlantic, Surinam } & Oct 2005 & $5.5^{\circ} \mathrm{N} 308.5^{\circ} \mathrm{E}$ & 1270 & id. \\
\hline & & North America & & \\
\hline UMBS, Michigan & Jun 2002 & $45.3^{\circ} \mathrm{N} 275.6^{\circ} \mathrm{E}$ & 6800 & Karl et al. (2003a) \\
\hline UMBS, Michigan & Jul-Aug 2005 & id. & 8050 & id. \\
\hline UMBS, Michigan & Sep-Oct 2001 & id. & 3530 & id. \\
\hline Trinidad Head, US & Apr-May 2002 & $41.0^{\circ} \mathrm{N} 235.8^{\circ} \mathrm{E}$ & 800 & Millet et al. (2004) \\
\hline Duke Forest, US & Jul 2003 & $36.0^{\circ} \mathrm{N} 280.1^{\circ} \mathrm{E}$ & 4800 & Karl et al. (2005) \\
\hline Blodgett Forest, US & Jun 2000 & $38.9^{\circ} \mathrm{N} 239.4^{\circ} \mathrm{E}$ & 4760 & Schade and Goldstein (2006) \\
\hline id. & Sep-Nov 2000 & id. & 3440 & id. \\
\hline id. & Dec-Jan 2000 & id. & 970 & id. \\
\hline id. & Mar 2001 & id. & 1900 & id. \\
\hline Thompson Farm, US & Jul-Aug 2004 & $43.1^{\circ} \mathrm{N} 289.0^{\circ} \mathrm{E}$ & 2500 & Mao et al. (2006) \\
\hline Appledore Isl., US & id. & $41.0^{\circ} \mathrm{N} 289.4^{\circ} \mathrm{E}$ & 2100 & id. \\
\hline \multirow[t]{2}{*}{ Chebogue Point } & id. & $43.7^{\circ} \mathrm{N} 293.9^{\circ} \mathrm{E}$ & 1389 & Millet et al. (2006) \\
\hline & & Europe & & \\
\hline Innsbruck, Austria & Sep 1997 & $47.2^{\circ} \mathrm{N} 11.3^{\circ} \mathrm{E}$ & 3000 & Holzinger et al. (2001) \\
\hline Creta, Greece & Aug 2001 & $35.0^{\circ} \mathrm{N} 25.2^{\circ} \mathrm{E}$ & 3500 & de Gouw et al. (2004) \\
\hline Athens, Greece & id. & $38.0^{\circ} \mathrm{N} 24.0^{\circ} \mathrm{E}$ & 4500 & id. \\
\hline Bremen, Germany & Jul 2004 & $53.1^{\circ} \mathrm{N} 8.8^{\circ} \mathrm{E}$ & 2200 & Solomon et al. (2005) \\
\hline Juelich, Germany & Jul 2003 & $50.9^{\circ} \mathrm{N} 6.4^{\circ} \mathrm{E}$ & 8000 & Spirig et al. (2005) \\
\hline Raunefjord, Norway & Jun 2005 & $60.3^{\circ} \mathrm{N} 5.3^{\circ} \mathrm{E}$ & 1860 & Sinha et al. (2007) \\
\hline Central Switzerland & Jul 2004 & $47.3^{\circ} \mathrm{N} 7.8^{\circ} \mathrm{E}$ & 6000 & Brunner et al. (2007) \\
\hline Zurich, Switzerland & Apr 2005 & $47.3^{\circ} \mathrm{N} 8.5^{\circ} \mathrm{E}$ & 2180 & Legreid et al. (2007) \\
\hline id. & Jul 2005 & id. & 3180 & id. \\
\hline id. & Nov 2005 & id. & 1110 & id. \\
\hline id. & Dec-Jan 2005 & id. & 1210 & id. \\
\hline Vielsalm, Belgium & Jul 2009 & $50.3^{\circ} \mathrm{N} 6.0^{\circ} \mathrm{E}$ & 4700 & Sect. 6.2 \\
\hline id. & Aug 2009 & id. & 4000 & id. \\
\hline id. & Sep 2009 & id. & 2600 & id. \\
\hline id. & Apr 2010 & id. & 2680 & id. \\
\hline id. & May 2010 & id. & 3000 & id. \\
\hline id. & Jun 2010 & id. & 4430 & id. \\
\hline id. & Jul 2010 & id. & 3810 & id. \\
\hline id. & Aug 2010 & id. & 2100 & id. \\
\hline \multirow[t]{2}{*}{ id. } & Sep 2010 & id. & 1770 & id. \\
\hline & & Marine & & \\
\hline Indian Ocean, $7.5^{\circ} \mathrm{N}$ & Mar 1999 & $7.5^{\circ} \mathrm{N} 70^{\circ} \mathrm{E}$ & 1417 & Wisthaler et al. (2002) \\
\hline Indian Ocean, $9-13^{\circ} \mathrm{N}$ & id. & $9-13^{\circ} \mathrm{N} 67-70^{\circ} \mathrm{E}$ & 1057 & id. \\
\hline Indian Ocean, $13-19^{\circ} \mathrm{N}$ & id. & $13-19^{\circ} \mathrm{N} 66-70^{\circ} \mathrm{E}$ & 687 & id. \\
\hline Indian Ocean, $0-13^{\circ} \mathrm{S}$ & id. & $0-13^{\circ} \mathrm{S} 71-73^{\circ} \mathrm{E}$ & 600 & id. \\
\hline Mauna Loa & Mar-Apr 2001 & $19.5^{\circ} \mathrm{N} 204.4^{\circ} \mathrm{E}$ & 900 & Karl et al. (2003b) \\
\hline Atlantic $1.7 \pm 1.3 \mathrm{~km}$ & Jul-Aug 2004 & $35.8-40.2^{\circ} \mathrm{N} 321.4-332.6^{\circ} \mathrm{E}$ & 530 & Lewis et al. (2007) \\
\hline Atlantic $2.4 \pm 1.4 \mathrm{~km}$ & id. & $36-44^{\circ} \mathrm{N} 326-338^{\circ} \mathrm{E}$ & 630 & id. \\
\hline Atlantic $3.5 \pm 1.7 \mathrm{~km}$ & id. & $40.5-45.5^{\circ} \mathrm{N} 325-335^{\circ} \mathrm{E}$ & 1100 & id. \\
\hline Atlantic $6.1 \pm 1.9 \mathrm{~km}$ & id. & $36.5-43.5^{\circ} \mathrm{N} 323-341^{\circ} \mathrm{E}$ & 680 & id. \\
\hline Atlantic $6.7 \pm 2.3 \mathrm{~km}$ & id. & $36.1-41.9^{\circ} \mathrm{N} 319.8-334.2^{\circ} \mathrm{E}$ & 380 & id. \\
\hline
\end{tabular}



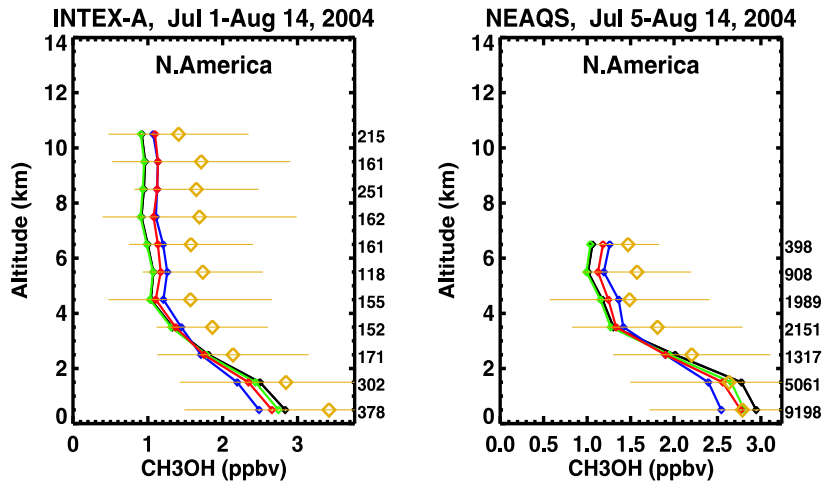

Fig. 14. Comparison between vertical profiles measured during the INTEX-A and NEAQS aircraft missions and inferred from the OptS2 (black lines), OptS2-conv (blue), OptS2-drydep (green), and OptS2-OH (red).
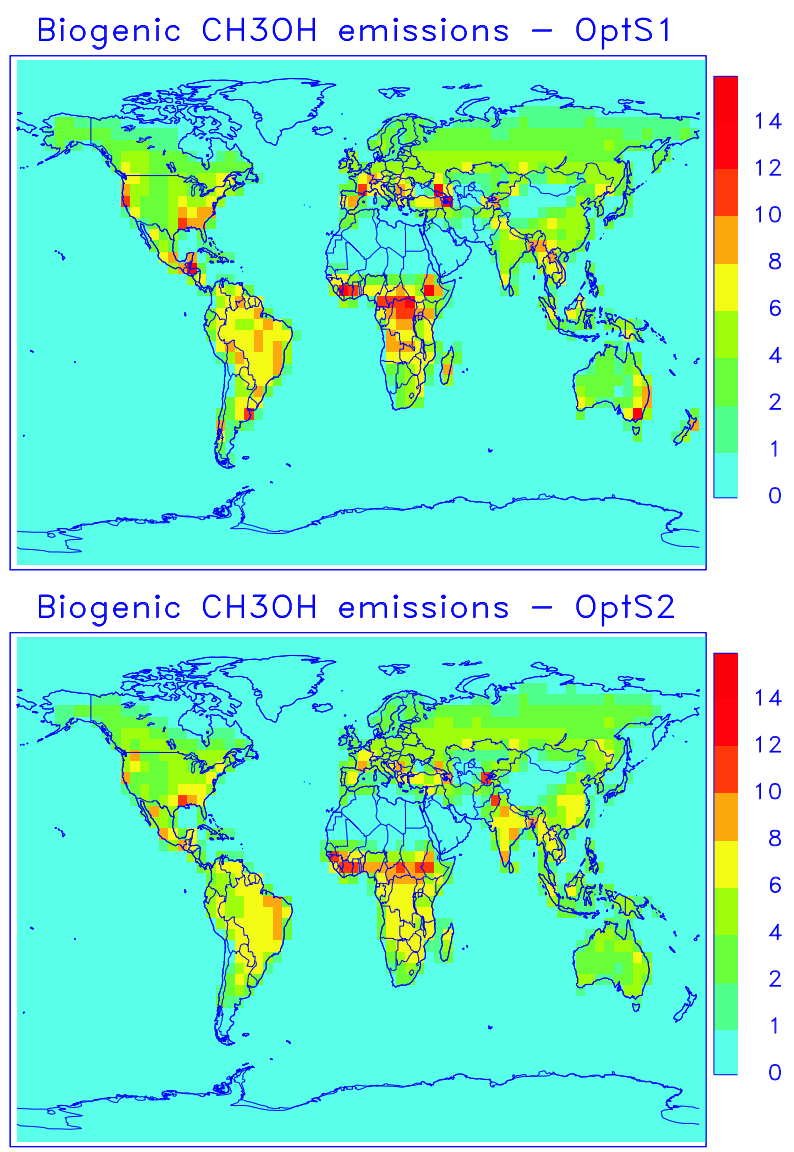

Fig. 15. Annually averaged biogenic methanol emissions derived by the inversion OptS1, which uses the Jacob et al. (2005) biogenic sources as a priori, and by the standard OptS2 inversion. Units are $10^{10} \mathrm{~mol} \mathrm{~cm}^{-2} \mathrm{~s}^{-1}$. plete year of global methanol column abundances retrieved from the IASI sounder has been used in order to evaluate the model in terms of magnitude and seasonal variation of methanol concentrations. The agreement between the IASI columns and the model is considerably improved when MEGANv2.1 is used, compared to the simulation using the Jacob et al. (2005) database. In the latter case, large model overestimations have been found, especially over tropical forests, in line with findings by Millet et al. (2008), whereas poorly reproduced seasonal variations in the Tropics indicate that the parameterization based on net primary productivity is not suitable in these regions. Using MEGANv2.1 as a priori inventory, we have conducted an inverse modelling experiment based on the adjoint of IMAGESv2 and constrained by IASI columns in order to improve the estimates of methanol emissions from plants and vegetation fires. The main conclusions drawn from this study are summarized below.

- The global a posteriori biogenic methanol source deduced from the inversion amounts to $100 \mathrm{Tg} \mathrm{yr}^{-1}$ and is very close to a priori value of $105 \mathrm{Tg} \mathrm{yr}^{-1}$. The methanol source from vegetation fires is also decreased by $20 \%$ globally with respect to the GFEDv3 database, but stronger decreases (up to a factor of two) are inferred over central and Southern Africa.

- Annual reductions of the biogenic methanol source are suggested by the IASI data over Amazonia and Indonesia, by $40-55 \%$ and $45-58 \%$, respectively. Over Amazonia, the derived source allows for a very satisfactory agreement with the satellite data, yet it leads to a model underprediction of about $20 \%$ with respect to a limited set of available surface methanol measurements. It appears plausible that the IASI columns might be biased low over tropical forests due to possible cloud contamination problems.

- An annual decrease by $20-25 \%$ of the biogenic methanol source is suggested over the Eastern US, leading to a good agreement with aircraft data in the boundary layer, while the model systematically underestimates the methanol concentrations in the free troposphere over land and ocean, in line with previous modelling studies. Possible reasons for this underestimation include an understimation in the Western US methanol source, an underestimation of convective fluxes, and/or an overestimation of $\mathrm{OH}$ simulated concentrations.

- The biogenic methanol source is strongly increased with respect to MEGANv2.1 over arid and semi-arid regions of Central Asia, Western US, and Northern Australia. This might be related to an underestimation of the methanol emission rate from shrub or to an unaccounted source of methanol specific to such environments in the MEGANv2.1 model. Ground-based measurements at Kitt Peak and aircraft measurements over the Western 
US confirm these conclusions. This result clearly underscores the need for local measurements in arid regions like Central Asia.

- Comparisons of the optimized methanol concentrations with independent measurements from other instruments show a very good consistency, lending good confidence to IASI columns. The satellite dataset is a valuable tool towards improving our knowledge on methanol sources and sinks on the global scale, and in particular, for many world regions where local measurements are currently missing.

- The most important error reductions are achieved for the biogenic emissions over the Former Soviet Union (67\%), South America (50\%), and globally (43\%). The errors for the vegetation fire source are reduced moderately ( $14 \%$ on the global scale). Furthermore, the derived emissions are found to be weakly dependent to changes in the meteorology, the a priori emissions, and the methanol sink processes.

Acknowledgements. IASI has been developed and built under the responsibility of the Centre National d'Etudes Spatiales (CNES, France). It is flown onboard the Metop satellites as part of the EUMETSAT Polar System. This work has been supported by the PRODEX programme of the European Space Agency funded by the Belgian Science Policy Office and the Fonds National de la Recherche Scientifique (FRS-FNRS F.4511.08).

Edited by: M. Kanakidou

\section{References}

Andreae, M. O. and Merlet, P.: Emission of trace gases and aerosols from biomass burning, Global Biogeochem. Cy., 15, 955-966, 2001.

Asher, W.: The sea-surface microlayer and its effect on global airsea gas transfer, in: The Sea Surface and Global Change, edited by: Peter, S. L. and Robert, A. D., Cambridge University Press, Cambridge, UK, 1997.

Baker, B., Guenther, A., Greenberg, J., and Fall, R.: Canopy level fluxes of 2-methyl-3-buten-2-ol, acetone, and methanol by a portable relaxed eddy accumulation system, Environ. Sci. Technol., 35(9), 1701-1708, 2001.

Beer, R., Shephard, M. W., Kulawik, S., Clough, S. A., Eldering, A., Bowman, K. W., Sander, S. P., Fisher, B. M., Payne, V. H., Luo, M., Osterman, G. B., and J. R. Worden : First satellite observations of lower tropospheric ammonia and methanol, Geophys. Res. Lett., 35, L09801, doi:10.1029/2008GL033642, 2008.

Boynard, A., Clerbaux, C., Coheur, P.-F., Hurtmans, D., Turquety, S., George, M., Hadji-Lazaro, J., Keim, C., and MeyerArnek, J.: Measurements of total and tropospheric ozone from IASI: comparison with correlative satellite, ground-based and ozonesonde observations, Atmos. Chem. Phys., 9, 6255-6271, doi:10.5194/acp-9-6255-2009, 2009.
Brunner, A., Ammann, C., Neftel, A., and Spirig, C.: Methanol exchange between grassland and the atmosphere, Biogeosciences, 4, 395-410, 2007, http://www.biogeosciences.net/4/395/2007/.

Clerbaux, C., Boynard, A., Clarisse, L., George, M., Hadji-Lazaro, J., Herbin, H., Hurtmans, D., Pommier, M., Razavi, A., Turquety, S., Wespes, C., and Coheur, P.-F.: Monitoring of atmospheric composition using the thermal infrared IASI/MetOp sounder, Atmos. Chem. Phys., 9, 6041-6054, doi:10.5194/acp-9-6041-2009, 2009.

Coheur, P.-F., Clarisse, L., Turquety, S., Hurtmans, D., and C. Clerbaux : IASI measurements of reactive trace species in biomass burning plumes, Atmos. Chem. Phys., 9, 5655-5667, doi:10.5194/acp-9-5655-2009, 2009.

Davison, B., Brunner, A., Ammann, C., Spirig, C., Jocher, M., and Neftel, A.: Cut-induced VOC emissions from agricultural grasslands, Plant Biol., 10(1), 76-85, 2008.

de Gouw, J., Warneke, C., Holzinger, R., Klupfel, T., and Williams, J.: Inter-comparison between airborne measurements of methanol, acetonitrile and acetone using two differently configured PTR-MS instruments, Inter. J. Mass Spectr., 239, 129137, 2004.

Dufour, G., Boone, C. D., Rinsland, C. P., and Bernath, P. F.: First space-borne measurements of methanol inside aged southern tropical to mid-latitude biomass burning plumes using the ACE-FTS instrument, Atmos. Chem. Phys., 6, 3463-3470, doi:10.5194/acp-6-3463-2006, 2006.

Dufour, G., Szopa, S., Hauglustaine, D. A., Boone, C. D., Rinsland, C. P., and Bernath, P. F.: The influence of biogenic emissions on upper-tropospheric methanol as revealed from space, Atmos. Chem. Phys., 7, 6119-6129, doi:10.5194/acp-7-61192007, 2007.

Emmons, L. K., Hauglustaine, D. A., Müller, J.-F., Carroll, M. A., Brasseur, G. P., Brunner, D., Stahelin, J., Thouret, V., and Marenco, A.: Data composites of airborne observations of tropospheric ozone and its precursors, J. Geophys. Res., 105, 20,49720,538, 2000.

Fall, R. and Benson, A. A.: Leaf methanol - the simplest natural product from plants, Trends Plant. Sci., 1(9), 296-301, 1996.

Folkers, A., Hüve, K., Ammann, C., Dindorf, T., Kesselmeier, J., Kleist, E., Kuhn, U., Uerlings, R., and Wildt, J.: Methanol emissions from deciduous tree species: dependence on temperature and light intensity, Plant Biol., 10 (1), 65-75, 2008.

Fukui, Y., and Doskey, P. V.: Air-surface exchange of nonmethane organic compounds at a grassland site: seasonal variations and stressed emissions, J. Geophys. Res., 103(D11), 13153-13168, 1998.

Galbally, I. E. and Kirstine, W.: The production of methanol by flowering plants and the global cycle of methanol, J. Atmos. Chem., 43(3), 195-229, 2002.

George, M., Clerbaux, C., Hurtmans, D., Turquety, S., Coheur, P.F., Pommier, M., Hadji-Lazaro, J., Edwards, D. P., Worden, H., Luo, M., Rinsland, C., and McMillan, W.: Carbon monoxide distributions from the IASI/METOP mission: evaluation with other space-borne remote sensors, Atmos. Chem. Phys., 9, 8317-8330, doi:10.5194/acp-9-8317-2009, 2009.

Geron, C., Guenther, A., Greenberg, J., Loescher, H. W., Clark, D., and Baker, B.: Biogenic volatile organic compound emissions from a lowland tropical wet forest in Costa Rica, Atmos. Envi- 
ron., 36, 3793-3802, 2002.

Geron, C., Guenther, A., Greenberg, J., Karl, T., and Rasmussen, R.: Biogenic volatile organic compound emissions from desert vegetation of the southwestern US, Atmos. Environ., 40, 16451660, 2006.

Guenther, A., Hewitt, C. N., Erickson, D., McKay, W. A., Pierce, T., Scholes, B., Steinbrecher, R., Tallamraju, R., Taylor, J., and Zimmerman, P.: A global model of natural volatile organic compound emissions, J. Geophys. Res., 100(D5), 8873-8892, 1995.

Guenther, A., Karl, T., Harley, P., Wiedinmyer, C., Palmer, P. I., and Geron, C.: Estimates of global terrestrial isoprene emissions using MEGAN (Model of Emissions of Gases and Aerosols from Nature), Atmos. Chem. Phys., 6, 3181-3210, doi:10.5194/acp-63181-2006, 2006.

Harley, P., Greenberg, J., Niinemets, U., and Guenther, A.: Environmental controls over methanol emission from leaves, Biogeosciences, 4(6), 1083-1099, 2007.

Heikes, B. G., Chang, W., Pilson, M. E. Q., Swift, E., Singh, H. B., Guenther, A., Jacob, D. J., and Brand, L.: Atmospheric methanol budget and ocean implication, Global Biogeochem. Cy., 16, 1133, doi:10.1029/2002GB001895, 2002.

Hofzumahaus, A., Rohrer, F., Lu, K. Bohn, B., Brauers, T., Chang, C., Fuchs, H., Holland, F., Kita, K., Kondo, Y., Li, X., Lou, S., Shao, M., Zeng, L., Wahner A., Zhang, Y.: Amplified Trace Gas Removal in the Troposphere, Science, 324, 5935, 1702-1704, doi:10.1126/science.1164566, 2009.

Holzinger, R., Jordan, A., Hansel, A., and Lindinger, W.: Methanol measurements in the lower troposphere near Innsbruck $\left(47^{\circ} 16^{\prime} \mathrm{N} ; 11^{\circ} 24^{\prime} \mathrm{E}\right)$, Austria, Atmos. Environ., 35, 2525-2532, 2001.

Hüve, K., Christ, M. M., Kleist, E., Uerlings, R., Niinemets, Ü., Walter, A., and Wildt, J.: Simultaneous growth and emission measurements demonstrate an interactive control of methanol release by leaf expansion and stomata, J. Exp. Bot., 58(7), 17831793, 2007.

ITTC Recommended Procedures and guidelines: Testing and Extrapolation Methods, General, Density and viscosity of water, Section 7.5-02-01-03, 2006.

Fletcher, R.: Practical Methods in Optimization, 2nd edn., Wiley, 1990.

Jacob, D. J., Field, B. D., Li, Q., Blake, D. R., de Gouw, J., Warneke, C., Hansel, A., Wisthaler, A., Singh, H. B., and Guenther, A.: Global budget of methanol: Constraints from atmospheric observations, J. Geophys. Res., 110, D08303, doi:10.1029/2004JD005172, 2005.

Jardine, K., Harley, P., Karl, T., Guenther, A., Lerdau, M., and Mak, J. E.: Plant physiological and environmental controls over the exchange of acetaldehyde between forest canopies and the atmosphere, Biogeosciences 5(6), 1559-1572, 2008.

Jardine, K., Abrell, L., Kurc, S. A., Huxman, T., Ortega, J., and Guenther, A.: Volatile organic compound emissions from Larrea tridentata (creosotebush), Atmos. Chem. Phys., 10, 1219112206, doi:10.5194/acp-10-12191-2010, 2010.

Johnson, M. T.: A numerical scheme to calculate temperature and salinity dependent air-water transfer velocities for any gas, Ocean Sci., 6, 913-932, 2010,

http://www.ocean-sci.net/6/913/2010/.

Karl, T. G., Spirig, C., Rinne, J., Stroud, C., Prevost, P., Greenberg, J., Fall, R., and Guenther, A.: Virtual disjunct eddy covari- ance measurements of organic compound fluxes from a subalpine forest using proton transfer reaction mass spectrometry, Atmos. Chem. Phys., 2, 279-291, doi:10.5194/acp-2-279-2002, 2002.

Karl, T., Guenther, A., Spirig, C. Hansel, A., and Fall, R.: Seasonal variation of biogenic VOC emissions above a mixed hardwood in northern Michigan, Geophys. Res. Lett., 30, 2186, doi:10.1029/2003GL018432, 2003a.

Karl, T., Hansel, A., Märk, T., Lindinger, W., and Hoffmann, D.: Trace gas monitoring at the Mauna Loa Baseline Observatory using Proton-Transfer Reaction Mass Spectrometry, Int. J. Mass Spec., 223-224, 527-538, 2003 b.

Karl, T., Potosnak, M., Guenther, A., Clark, D., Walker, J., Herrick, J. D., and Geron, C.: Exchange processes of volatile organic compounds above a tropical rain forest: Implications for modelling troposheric chemistry above dense vegetation, J. Geophys. Res., 109, D18306, doi:10.1029/2004JD004738, 2004.

Karl, T., Harley, P., Guenther, A., Rasmussen, R., Baker, B., Jardine, K., and Nemitz, E.: The bi-directional exchange of oxygenated VOCs between a loblolly pine (Pinus taeda) plantation and the atmosphere, Atmos. Chem. Phys., 5, 3015-3031, doi:10.5194/acp-5-3015-2005, 2005.

Karl, T., Guenther, A., Yokelson, R. J., Greenberg, J., Potosnak, M., Blake, D. R., and Artaxo, P.: The tropical forest and fire emissions experiment, Emission, chemistry, and transport of biogenic volatile organic compounds in the lower atmosphere over Amazonia, J. Geophys. Res., 112, D18302, doi:10.1029/2007JD008539, 2007.

Karl, T., Harley, P., Emmons, L., Thornton, B., Guenther, A., Basu, C., Turnipseed, A., and Jardine, K.: Efficient Atmospheric Cleansing of Oxidized Organic Trace Gases by Vegetation, Science, 330, 816-819, 2010.

Kesselmeier, J., Kuhn, U., Rottenberger, S., Biesenthal, T., Wolf, A., Schebeske, G., Andreae, M. O., Ciccioli, P., Brancaleoni, E., Frattoni, M., Oliva, S. T., Botelho, M. L., Silva, C. M. A., and Tavares, T. M.: Concentrations and species composition of atmospheric volatile organic compounds (VOCs) as observed during the wet and dry season in Rondônia (Amazonia), J. Geophys Res., 107(D20), 8053, doi:10.1029/2000JD000267, 2002.

Kirstine, W., Galbally, I., Ye, Y., and Hooper, M.: Emissions of volatile organic compounds (primarily oxygenated species) from pasture, J. Geophys. Res., 103(3339), 10605-10619, 1998.

Körner, E., von Dahl, C. C., Bonaventure, G., and Baldwin, I. T.: Pectin methylesterase NaPME1 contributes to the emission of methanol during insect herbivory and to the elicitation of defence responses in Nicotiana attenuata, J. Exp. Bot., 60(9), 26312640, doi:10.1093/jxb/erp106, 2009.

Laffineur, Q., Heinesch, B., Schoon, N., Amelynck, C., Müller, J.F., Dewulf, J., Van Langenhove, H., Steppe, K., Simpraga, M., and Aubinet, M.: Isoprene and monoterpene emissions from a mixed temperate forest, Atmos. Environ., 45, 3157-3168, 2010.

Langford, B., Misztal, P. K., Nemitz, E., Davison, B., Helfter, C., Pugh, T. A. M., MacKenzie, A. R., Lim, S. F., and Hewitt, C. N.: Fluxes and concentrations of volatile organic compounds from a South-East Asian tropical rainforest, Atmos. Chem. Phys., 10, 8391-8412, doi:10.5194/acp-10-8391-2010, 2010.

Legreid, G., Balzani Lööv, J., Staehelin, J., Hueglin, C., Hill, M., Buchmann, B., Prevot, A. S. H., and Reimann, S.: Oxygenated volatile organic compounds (OVOCs) at an urban background site in Zürich (Europe): Seasonal variation and source allocation, 
Atmos. Environ., 41, 8409-8423, 2007.

Lelieveld, J., Butler, T. M., Crowley, J. N., Dillon, T. J., Fischer, H., Ganzeveld, L., Harder, H., Lawrence, M. G., Martinez, M., Taraborrelli, D., and Williams, J.: Atmospheric oxidation capacity sustained by a tropical forest, Nature, 452, 737-740, doi:10.1038/nature06870, 2008.

Lewis, A. C., Evans, M. J., Methven, J., Watson, N., Lee, J. D., Hopkins, J. R., Purvis, R. M., Arnold, S. R., McQuaid, J. B., Whalley, L. K., Pilling, M. J., Heard, D. E., Monks, P. S., Parker, A. E., Reeves, C. E., Oram, D. E., Mills, G., Bandy, B. J., Stewart, D., Coe, H., Williams, P., Crosier, J.: Chemical composition observed over the mid-Atlantic and the detection of pollution signatures far from source regions, J. Geophys. Res., 112, D10S39, doi:10.1029/2006JD007584, 2007.

Liss, P. S. and Slater, P. G.: Flux of gases across air-sea interface, Nature, 247, 181-184, 1974.

Macdonald, R. C. and Fall, R.: Detection of substantial emissions of methanol from plants to the atmosphere, Atmos. Environ., 27(11), 1709-1713, 1993.

Mao, H., Talbot, R., Nielsen, C., and Sive, B.: Controls on methanol and acetone in marine and continental atmospheres, Geophys. Res. Lett., 33, L02803, doi:10.1029/2005GL024810, 2006.

Millet, D. B., Goldstein, A. H., Allan, J. D., Bates, T. S., Boudries, H., Bower, K. N., Coe, H., Ma, Y., McKay, M., Quinn, P. K., Sullivan, A., Weber, R. J., Worsnop, D. R.: Volatile organic compound measurements at Trinidad Head, California, during ITCT 2K2: Analysis of sources, atmospheric composition, and aerosol residence times, J. Geophys. Res., 109, D23S16, doi:10.1029/2003JD004026, 2004.

Millet, D. B., Goldstein, A. H., Holzinger, R., Allan, J. D., Jimenez, J. L., Worsnop, D. R., Roberts, J. M., White, A. B., Hudman, R. C., Bertschi, I. T., Stohl, A.: Chemical characteristics of North American surface layer outflow: Insights from Chebogue Point, Nova Scotia, J. Geophys. Res., 111, D23S53, doi:10.1029/2006JD007287, 2006.

Millet, D. B., Jacob, D. J., Custer, T. G., de Gouw, J. A., Goldstein, A. H., Karl, T., Singh, H. B., Sive, B. C., Talbot, R. W., Warneke, C., and Williams, J.: New constraints on terrestrial and oceanic sources of atmospheric methanol, Atmos. Chem. Phys., 8, 68876905, doi:10.5194/acp-8-6887-2008, 2008.

Molina, L. T., Madronich, S., Gaffney, J. S., Singh, H. B., and U. Pöschl (Eds.): MILAGRO/INTEX-B 2006, Special Issue, Atmos. Chem. Phys., http://www.atmos-chem-phys.net/special_ -issue83.html, 2007-2010.

Müller, J.-F. and Stavrakou, T.: Inversion of $\mathrm{CO}$ and $\mathrm{NO}_{x}$ emissions using the adjoint of the IMAGES model, Atmos. Chem. Phys., 5, 1157-1186, doi:10.5194/acp-5-1157-2005, 2005.

Müller, J.-F., Stavrakou, T., Wallens, S., De Smedt, I., Van Roozendael, M., Potosnak, M. J., Rinne, J., Munger, B., Goldstein, A., and Guenther, A. B.: Global isoprene emissions estimated using MEGAN, ECMWF analyses and a detailed canopy environment model, Atmos. Chem. Phys., 8, 1329-1341, doi:10.5194/acp-81329-2008, 2008.

Niinemets, Ü. and Reichstein, M.: Controls on the emission of plant volatiles through stomata : Differential sensitivity of emission rates to stomatal closure explained, J. Geophys. Res., 108, 4208, doi:10.1029/2002JD002620, 2003a.

Niinemets, Ü. and M. Reichstein : Controls on the emission of plant volatiles through stomata: A sensitivity analysis, J. Geo- phys. Res., 108, 4211, doi:10.1029/2002JD002626, $2003 \mathrm{~b}$.

Nemecek-Marshall M., MacDonald, R. C., Franzen, J. J., Wojciechowski, C. L., and Fall, R.: Methanol emission from leaves. Enzymatic detection of gas-phase methanol and relation of methanol fluxes to stomatal conductance and leaf development, Plant Physiol., 108, 1359-1368, 1995.

Ohara, T., Akimoto, H., Kurokawa, J., Horii, N., Yamaji, K., Yan, X., and Hayasaka, T.: An Asian emission inventory of anthropogenic emission sources for the period 1980-2020, Atmos. Chem. Phys., 7, 4419-4444, doi:10.5194/acp-7-4419-2007, 2007.

Razavi, A., Karagulian, F., Clarisse, L., Hurtmans, D., Coheur, P. F., Clerbaux, C., Müller, J. F., and Stavrakou, T.: Global distributions of methanol and formic acid retrieved for the first time from the IASI/MetOp thermal infrared sounder, Atmos. Chem. Phys., 11, 857-872, doi:10.5194/acp-11-857-2011, 2011.

Ren, X., Olson, J. R., Crawford, J. H., Brune, W. H., Mao, J., Long, R. B., Chen, Z., Chen, G., Avery, M. A., Sachse, G. W., Barrick, J. D., Diskin, G. S., Huey, L. G., Fried, A., Cohen, R. C., Heikes, B., Wennberg, P. O., Singh, H. B., Blake, D. R., Shetter, R. E.: $\mathrm{HO}_{\mathrm{x}}$ chemistry during INTEX-A 2004: Observation, model calculation, and comparison with previous studies, J. Geophys. Res., 113, D05310, doi:10.1029/2007JD009166, 2008.

Rinne, J., Taipale, R., Markkanen, T., Ruuskanen, T. M., Hellén, H., Kajos, M. K., Vesala, T., and Kulmala, M.: Hydrocarbon fluxes above a Scots pine forest canopy: measurements and modeling, Atmos. Chem. Phys., 7, 3361-3372, doi:10.5194/acp-73361-2007, 2007.

Rinsland, C. P., Jones, N. B., and Connor, B. J.: Northern and southern hemisphere ground-based infrared spectroscopic measurements of tropospheric carbon monoxide and ethane, J. Geophys. Res., 103(D21), 28,197-28,217, 1998.

Rinsland, C. P., E. Mahieu, L. Chiou, and H. Herbin : First ground-based infrared solar absorption measurements of free tropospheric methanol $\left(\mathrm{CH}_{3} \mathrm{OH}\right)$ : Multidecade infrared time series from Kitt Peak $\left(31.9^{\circ} \mathrm{N} 111.6^{\circ} \mathrm{W}\right)$ : Trend, seasonal cycle, and comparison with previous measurements, J. Geophys. Res., 114, D04309, doi:10.1029/2008JD011003, 2009.

Ruuskanen, T. M., Müller, M., Schnitzhofer, R., Karl, T., Graus, M., Bamberger, I., Hörtnagl, L., Brilli, F., Wohlfahrt, G., and Hansel, A.: Eddy covariance VOC emission and deposition fluxes above grassland using PTR-TOF, Atmos. Chem. Phys. Discuss., 10, 21,077-21,108, doi:10.5194/acpd-10-21077-2010, 2010.

Sander, R.: Compilation of Henry's Law Constants for Inorganic and Organic Species of Potential Importance in Environmental Chemistry (Version 3), http://www.mpch-mainz.mpg.de/ \%7Esander/res/henry.html, 1999.

Sanhueza, E., Holzinger, R., Donoso, L., Santana, M., Fernandez, E., and Romero, J.: Compuestos organicos volantiles en la atmosfera Gran Sabana, concentraciones y quimica atmosferica, Interciencia, 26, 597-605, 2001.

Schade, G. W. and Custer, T. G.: OVOC emissions from agricultural soil in northern Germany during the 2003 European heat wave, Atmos. Environ., 38(36), 6105-6114, 2004.

Schade, G. W. and Goldstein, A. H.: Fluxes of oxygenated volatile organic compounds from a ponderosa pine plantation, J. Geophys. Res., 106(D3), 3111-3123, 2001.

Schade, G. W. and Goldstein, A. H.: Seasonal measurements of acetone and methanol: abundances and implications for 
atmospheric budgets, Global Biogeochem. Cy., 20, GB1011, doi:10.1029/2005GB002566, 2006.

Schink, B. and Zeikus, J. G.: Microbial methanol formation: A major end product of pectin metabolism, Curr. Microbiol., 4(6), 387-389, 1980.

Seco, R., Peñuelas, J., and Filella, I.: Short-chain oxygenated VOCS: Emission and uptake by plants and atmospheric sources, sinks and concentrations, Atmos. Environ., 41(12), 2477-2499, 2007.

Senten, C., De Mazière, M., Dils, B., Hermans, C., Kruglanski, M., Neefs, E., Scolas, F., Vandaele, A. C., Vanhaelewyn, G., Vigouroux, C., Carleer, M., Coheur, P. F., Fally, S., Barret, B., Baray, J. L., Delmas, R., Leveau, J., Metzger, J. M., Mahieu, E., Boone, C., Walker, K. A., Bernath, P. F., and Strong, K.: Technical Note: New ground-based FTIR measurements at Ile de La Réunion: observations, error analysis, and comparisons with independent data, Atmos. Chem. Phys., 8, 3483-3508, doi:10.5194/acp-8-3483-2008, 2008.

Shabanov, N., Samanta, A., Myneni, R. B., Knyazikhin, Y., Votava, P., Nemani, R.: Collection 5 MODIS LAI and FPAR Products, University of Maryland, http://modis.gsfc.nasa.gov/ sci_team/meetings/c5meeting/pres/day1/shabanov.pdf, 2007.

Singh, H. B., Kanakidou, M., Krutzen, P. J., and Jacob, D. J.: High concentrations and photochemical fate of oxygenated hydrocarbons in the global troposphere, Nature, 378, 50-54, 1995.

Singh, H. B., Tabazadeh, A., Fukui, Y., Bey, I., Yantosca, R., Jacob, D., Arnold, F., Wohlfrom K., Atlas, E., Flocke, F., Blake, D., Blake, N., Heikes, B., Snow, J., Talbot, R., Gregory, G., Sachse, G., Vay, S., Kondo, Y.: Distribution and fate of selected oxygenated organic species in the troposphere and lower stratosphere over the Atlantic, J. Geophys. Res., 105(D3), 3795-3805, 2000.

Singh, H. B., Chen, Y., Staudt, A., Jacob, D., Blake, D., Heikes, B., and Snow, J.: Evidence from the Pacific troposphere for large global sources of oxygenated organic compounds, Nature, 410, 1078-1081, 2001.

Singh, H. B., Tabazadeh, A., Evans, M. J., Field, B. D., Jacob, D. J., Sachse, G., Crawford, J. H., Shetter, R., and Brune, W. H.: Oxygenated volatile organic chemicals in the oceans : Inferences and implications based on atmospheric observations and air-sea exchange models, Geophys. Res. Lett., 30(16), 1862, doi:10.1029/2003GL017933, 2003.

Singh, H. B., Brune, W. H., Crawford, J. H., Jacob, D. J., and Russell, P. B.: Overview of the summer 2004 Intercontinental Chemical Transport Experiment - North America (INTEX-A), J. Geophys. Res., 111, D24S01, doi:10.1029/2006JD007905, 2006.

Sinha, V., Williams, J., Meyerhöfer, M., Riebesell, U., Paulino, A. I., and Larsen, A.: Air-sea fluxes of methanol, acetone, acetaldehyde, isoprene and DMS from a Norwegian fjord following a phytoplankton bloom in a mesocosm experiment, Atmos. Chem. Phys., 7, 739-755, doi:10.5194/acp-7-739-2007, 2007.

Snider, J. R., and Dawson, G. A.: Tropospheric light alcohols, carbonyls, and acetonitrile: Concentrations in the southwestern United States and Henry's law data, J. Geophys. Res., 90, $3797-$ 3805, 1985.

Solomon, S. J., Custer, T., Schade, G., Soares Dias, A. P., and Burrows, J.: Atmospheric methanol measurement using selective catalytic methanol to formaldehyde conversion, Atmos. Chem. Phys., 5, 2787-2796, doi:10.5194/acp-5-2787-2005, 2005.

Spirig, C., Neftel, A., Ammann, C., Dommen, J., Grabmer,
W., Thielmann, A., Schaub, A., Beauchamp, J., Wisthaler, A., and Hansel, A.: Eddy covariance flux measurements of biogenic VOCs during ECHO 2003 using proton transfer reaction mass spectrometry, Atmos. Chem. Phys., 5, 465-481, doi:10.5194/acp-5-465-2005, 2005.

Spivakovsky, C. M., Yevich, R., Logan, J. A., Wofsy, S. C., McElroy, M. B., and Prather, M. J.: Tropospheric $\mathrm{OH}$ in a threedimensional chemical tracer model: An assessment based on observations of $\mathrm{CH}_{3} \mathrm{CCl}_{3}$. J. Geophys. Res., 95, 18441-18471, doi:10.1029/90JD01299, 1990.

Stavrakou, T. and Müller, J.-F.: Grid-based versus big region approach for inverting CO emissions using Measurement of Pollution in the Troposphere (MOPITT) data, J. Geophys. Res., 111, D15304, doi:10.1029/2005JD006896, 2006.

Stavrakou, T., Müller, J.-F., Boersma, F., De Smedt, I., and van der A, R.: Assessing the distribution and growth rates of $\mathrm{NO}_{\mathrm{x}}$ emission sources by inverting a 10-year record of $\mathrm{NO}_{2}$ satellite columns, Geophys. Res. Lett., 35, L10810, doi:10.1029/2008GL033521, 2008.

Stavrakou, T., Müller, J.-F., De Smedt, I., Van Roozendael, M., van der Werf, G. R., Giglio, L., and Guenther, A.: Evaluating the performance of pyrogenic and biogenic emission inventories against one decade of space-based formaldehyde columns, Atmos. Chem. Phys., 9, 1037-1060, doi:10.5194/acp-9-1037-2009, 2009.

Stavrakou, T., Mller, J.-F., De Smedt, I., Van Roozendael, M., Kanakidou, M., Vrekoussis, M., Wittrock, F., Richter, A., and Burrows, J. P.: The continental source of glyoxal estimated by the synergistic use of spaceborne measurements and inverse modelling, Atmos. Chem. Phys., 9, 8431-8446, doi:10.5194/acp-9-8431-2009, 2009.

Stavrakou, T., Müller, J.-F., De Smedt, I., Van Roozendael, M., van der Werf, G. R., Giglio, L., and Guenther, A. Global emissions of non-methane hydrocarbons deduced from SCIAMACHY formaldehyde columns through 2003-2006, Atmos. Chem. Phys., 9, 3663-3679, doi:10.5194/acp-9-3663-2009, 2009.

Stavrakou, T., Peeters, J., and Müller, J.-F.: Improved global modelling of $\mathrm{HO}_{\mathrm{x}}$ recycling in isoprene oxidation: evaluation against the GABRIEL and INTEX-A aircraft campaign measurements, Atmos. Chem. Phys., 10, 9863-9878, doi:10.5194/acp-10-98632010, 2010.

Tie, X., Guenther, A., and Holland, E.: Biogenic methanol and its impacts on tropospheric oxidants, Geophys. Res. Lett., 30(17), 1881, doi:10.1029/2003GL017167, 2003.

Tikhonov, A.: On the solution of incorrectly stated problems and a method of regularization, Dokl. Acad. Nauk SSSR, 151, 501504, 1963.

van der Werf, G. R., Randerson, J. T., Giglio, L., Collatz, G. J., Mu, M., Kasibhatla, P. S., Morton, D. C., DeFries, R. S., Jin, Y., and van Leeuwen, T. T.: Global fire emissions and the contribution of deforestation, savanna, forest, agricultural, and peat fires (19972009), Atmos. Chem. Phys., 10, 11707-11735, doi:10.5194/acp10-11707-2010, 2010.

Vigouroux, C., Hendrick, F., Stavrakou, T., Dils, B., De Smedt, I., Hermans, C., Merlaud, A., Scolas, F., Senten, C., Vanhaelewyn, G., Fally, S., Carleer, M., Metzger, J.-M., Müller, J.-F., Van Roozendael, M., and De Mazière, M.: Ground-based FTIR and MAX-DOAS observations of formaldehyde at Réunion Island 
and comparisons with satellite and model data, Atmos. Chem. Phys., 9, 9523-9544, doi:10.5194/acp-9-9523-2009, 2009.

Warneke, C., Karl, T., Judmaier, H., Hansel, A., Jordan, A., Lindinger, W., and Crutzen, P.: Acetone, Methanol, and Other Partially Oxidized Volatile Organic Emissions From Dead Plant Matter by Abiological Processes: Significance for Atmospheric $\mathrm{HO}_{\mathrm{x}}$ Chemistry, Global Biogeochem. Cy., 13(1), 9-17, 1999.

Warneke, C., Luxembourg, S. L., De Gouw, J. A., Rinne, H. J. I., Guenther, A., and Fall, R.: Disjunct eddy covariance measurements of oxygenated volatile organic compounds fluxes from an alfalfa field before and after cutting, J. Geophys. Res., 107, D8, doi:10.1029/2001JD000594, 2002.

Williams, J., Pöschl, U., Crutzen, P. J., Hansel, A., Holzinger, R., Warneke, C., Lindinger, W., and Lelieveld, J.: An atmospheric Chemistry interpretation of mass scans obtained from a proton transfer mass spectrometer flown over the tropical rainforest of Surinam, J. Atmos. Chem., 38, 133-166, 2001.
Williams, J., Holzinger, R., Gros, V., Xu, X., Atlas, E., and Wallace, D. W. R.: Measurements of organic species in air and seawater from the tropical Atlantic, Geophys. Res. Lett., 31, L23S06, doi:10.1029/2004GL020012, 2004.

Wisthaler, A., Hansel, A., Dickerson, R. R., and Crutzen, P. J.: Organic trace gas measurements by PTR-MS during INDOEX 1999, J. Geophys. Res., 107(D19), 8024, doi:10.1029/2001JD000576, 2002.

Zhang, P., Anderson, M., Barlow, B., Tan, B., and Myneni, R. B.: Climate-related vegetation characteristics derived from Moderate Resolution Imaging Spectroradiometer (MODIS) leaf area index and normalized difference vegetation index, J. Geophys. Res., 109, D20105, doi:10.1029/2004JD004720, 2004. 